Research Article

\title{
Investigation of Damage Diagnosis of Retaining Wall Structures Based on the Hilbert Damage Feature Vector Spectrum
}

\author{
Qian Xu ii \\ School of Civil Engineering and Architecture, Shaanxi University of Technology, Hanzhong 723000, China \\ Correspondence should be addressed to Qian Xu; xuqian20121601014@163.com
}

Received 6 July 2019; Revised 23 August 2019; Accepted 14 September 2019; Published 7 October 2019

Academic Editor: Pedro Galvín

Copyright (C) 2019 Qian Xu. This is an open access article distributed under the Creative Commons Attribution License, which permits unrestricted use, distribution, and reproduction in any medium, provided the original work is properly cited.

To diagnose damages within the retaining wall structure, the Hilbert marginal energy spectrum was acquired via the Hilbert-Huang transformation of virtual impulse response functions of responses to the retaining wall under ambient excitations. Based on the Hilbert marginal energy spectrum, the Hilbert damage feature vector spectrum was created. On the basis of the damage feature vector spectrum, a damage identification index was proposed. Based on the damage feature vector spectrum and damage index, the damage state of the retaining wall was detected by the damage feature vector spectrum, damage locations of the wall were diagnosed by the damage index trend surface, and the damage intensity of the wall was identified by the quantitative relationship between the damage index and damage intensity. Based on this, a damage diagnosis method for retaining wall structures was proposed. To verify the feasibility and validity of the damage diagnosis method, both model tests and field tests on a pile plate retaining wall are performed under ambient excitations. Test results show that the damage state of the wall can be detected sensitively, damage locations can be diagnosed validly, and damage intensity can be identified quantitatively via this damage diagnosis method.

\section{Introduction}

Retaining walls, as a common type of retaining structures, were widely used in building engineering, transportation engineering, underground engineering, and related fields. Due to material degradation, variations of surroundings (such as a variation of temperature or humidity), and variations of loads, numerous types of damages (such as cracks or holes) might appear and accumulate in walls. These damages might cause collapse or failure of the wall, if these damages were not found in time and repaired efficiently. Once these retaining walls, such walls with high danger and significance as pile plate retaining walls used to support deep ditch, under consistent walls used to support under structures, and walls used in high slopes, collapsed, major accidents might occur, as shown in Table 1 and Figure 1 [1]. From Table 1, collapse of the walls was mainly caused by the rainfall, construction quality faults, and damages. Moreover, many accident investigations show that damages will occur and accumulate continuously within retaining walls under the comprehensive effects of many factors. The damages may not only reduce the life span of walls but also cause collapse or failure of walls, if these damages are not detected and repaired on time. Thus, it is necessary and significant to detect damages within retaining walls to avoid or reduce similar accidents in the future.

Thus far, the majority of studies on damage identification have focused on structural components [2-4], building structures [5, 6], bridge structures [7, 8], and other structures $[9,10]$. Because the retaining wall structure system is constituted by the wall and soil, it is difficult to analyze the complicated interaction between the wall and soil. Thus, the damage identification research on retaining wall structures is much rarer. So, damage diagnosis for retaining walls should be paid much attention.

Common damages within engineering structures mainly include internal faults, structural cracks, holes, and others. These damages mainly cause changes of some parameters which are used to reflect structural characteristics. Thus, these structural parameters are identified and analyzed to 
TABLe 1: Accidents of retaining wall collapse.

\begin{tabular}{|c|c|c|c|}
\hline Time & Place & Consequence & Cause \\
\hline 2012 & Shenwu city of Fujian Province, China & Destruction of many houses & Damages were not fund and repaired timely \\
\hline 2013 & Shouyang city of Shanxi Province, China & 12 deaths and 7 injuries & $\begin{array}{c}\text { Damages were not paid much attention after } \\
\text { detecting damages }\end{array}$ \\
\hline 2014 & Qingdao city of Shandong Province, China & 18 deaths and several injures & Damages caused by rainfall cause collapse of the wall \\
\hline 2015 & Lanling city of Shandong Province, China & 10 deaths and 3 injures & Construction quality faults cause collapse of the wall \\
\hline 2016 & Quanzhou city of Fujian Province, China & 2 deaths and 6 injures & $\begin{array}{l}\text { Rainfall and construction quality faults cause collapse } \\
\text { of the wall }\end{array}$ \\
\hline
\end{tabular}

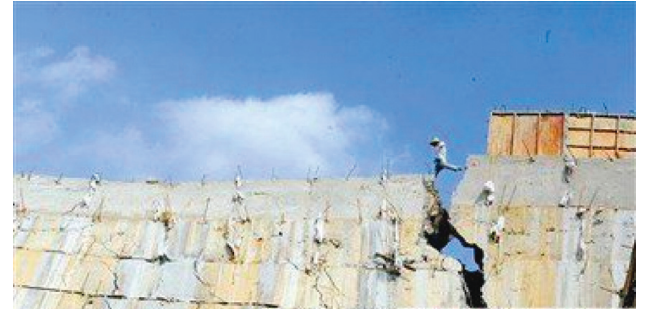

(a)

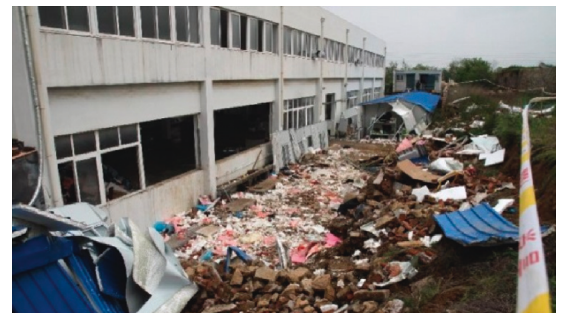

(c)

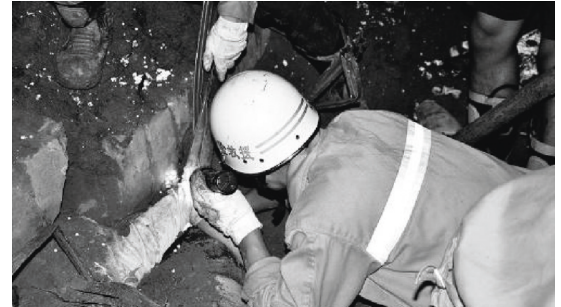

(b)

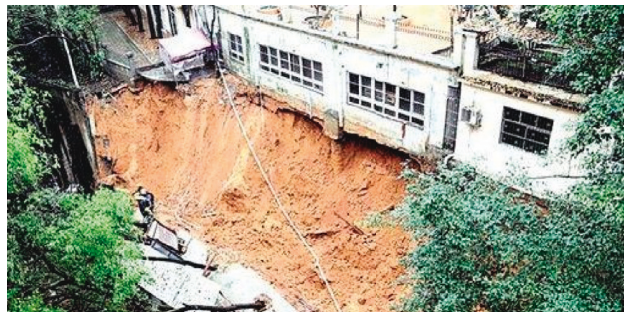

(d)

Figure 1: Accidents of retaining wall collapse (the photos above from the internet). (a) Retaining wall in Shenwu city. (b) Retaining wall in Shouyang city. (c) Retaining wall in Qingdao city. (d) Retaining wall in Quanzhou city.

detect damage state of structures, diagnose damage locations, identify damage intensity, and evaluate residual life span [11]. To identify damages, common damage diagnosis methods mainly include the methods based on structural dynamic parameters, methods based on the model updating, methods based on the intelligence algorithm, and methods based on response signals. Because such dynamic parameters as frequencies and mode shapes can be easily acquired, the damage identification methods based on structural parameters are widely used to detect damages. In 1979, Cawley and Adams detected damages within structures by the natural frequency variation caused by damage [12]. Biswas et al. [13] and Hearn and Testa [14] identified damages in structures and bridges, respectively, by modal variation. In 1996, Doebling noted that damages within structures could be detected from changes in structural characteristics [11]. Based on the finite model updating, Zhang et al. [15] and Zong et al.[16] identified damages within building structures and bridge structures via this method, respectively. The intelligence algorithm mainly includes the genetic algorithm and neural network. Via the damage identification method based on the genetic algorithm, Chou and Ghaboussi [17], Huang and Ren [18] identified damages within structures. They found that the damage location and damage intensity can be detected via this method when measurement information is insufficient. In addition, $\mathrm{Qu}$ and Chen [19], and Wang [20] et al. identified damages within frame structures via the damage diagnosis method based on the neural network. They found that the method had much stronger robustness and fault tolerance. Via the analysis of vibration signals in structures, damages can be detected. Hou et al.[21] identified damages within the Benchmark structure via the wavelet packet decomposition of structural vibration signals; Ding et al. proposed a damage alarming method for structures based on the wavelet packet energy spectrum [22, 23]. Zheng and Cheng [24] detected faults in bearings via the HilbertHuang transformation of vibration signals of the bearings. Ding et al. diagnosed the damage in beam structures via HHT (the Hilbert-Huang transformation) of vibration signals, and they found that this method had much stronger noise immunity [25].

Every damage diagnosis method has advantages and disadvantages. Because the dynamic parameters can be easily acquired, the method based on structural parameters is widely used to detect damages. However, It is easy to measure modal characteristics with lower order, but hard to measure ones with higher order via this method due to the limitation of existing testing technology. Some damage information might be lost via this method. Based on a 
practical structure, a finite element model of this structure is established. The damages within this structure can be identified via variation of partial stiffness. Nevertheless, under the influences of boundary conditions, material characteristics, and contact conditions, it is difficult to establish the numerical model, which can represent true characteristics of the structure. In addition, this method, which required better environments and excitations, is not suitable for the practical engineering with pool conditions and several interferences. The damage identification method based on the intelligence algorithm is affected greatly by sample functions, objective functions, and algorithms. The precision of damage identification is determined by these factors. Via the wavelet packet analysis of response signals, damage information can be acquired. This method, which has much better damage sensitivity and stronger noise immunity, is proved to be a potential damage identification method. However, the method lacks adaptivity to signals and is only suitable for linear signals. In addition, the wavelet packet analysis results are greatly dependent on the wavelet basis function. In comparison with WPT (the wavelet packet transform), the method based on HHT has good adaptivity to signals and is suitable for either linear signals or nonlinear ones [26].

Regarding as lack of damage identification researches on retaining wall structures at present, a diagnosis damage method for the retaining wall structure is proposed to identify damages within the wall in this paper. Firstly, EMD (the empirical mode decomposition) of virtual impulse response functions of responses to a retaining wall is performed to obtain the intrinsic mode functions under ambient excitations. Secondly, the Hilbert marginal energy spectrum was obtained by HT (the Hilbert transform) of the intrinsic mode functions. On the basis of the Hilbert marginal energy spectrum, the Hilbert feature vector spectrum is created. Based on the Hilbert feature vector spectrum, the Hilbert damage feature vector spectrum is created. On the basis of the damage feature vector spectrum, a damage identification index was proposed. Thirdly, based on the damage feature vector spectrum and damage index, a damage diagnosis method for retaining wall structures was proposed. Finally, the feasibility and validity of the damage diagnosis method are verified via model tests and field tests.

\section{Damage Diagnosis Method}

To obtain dynamic responses to a retaining wall, the wall must be applied excitations. To acquire useful response signals, the wall with big volume and large mass must be loaded much larger excitations via special equipment. However, the larger excitations may cause additional damages in the wall. In comparison with artificial excitations, the ambient excitations require ordinary equipment and few test instruments. In fact, much structural vibration is caused by such ambient excitations as wind loads, seismic loads, blast loads, mechanic vibration loads, dynamic loads of the vehicles, or their combinations. Thus, the way of applying ambient excitations is very suitable for exciting retaining walls. Under the ambient excitations, the energy spectrum based on dynamic response signals has much larger randomness, because the energy spectrum, which is directly based on dynamic response signals, is not the inherent characteristic of the structure. Thus, the energy spectrum based on dynamic response signals, which changes with variations of ambient excitations, is not suitable for detecting damages within the retaining wall. However, the energy spectrum based on the virtual impulse functions of responses to structures has much better robustness and sensitivity to damages because the virtual impulse response function (or the virtual frequency response function) is the inherent characteristic of structure [27]. Thus, the intrinsic mode functions can be obtained via the empirical mode decomposition of virtual impulse response functions of responses to the retaining wall under ambient excitations. Based on the intrinsic mode functions, the Hilbert marginal energy spectrum is acquired.

To obtain intrinsic mode functions, the empirical mode decomposition of $H(t)_{\mathrm{u}}$ and $H(t)_{\mathrm{d}}$ is performed, respectively.

$$
\begin{aligned}
& H(t)_{\mathrm{u}}=\left\{\mathrm{IMF}_{\mathrm{u}}=\mathrm{IMF}_{1 \mathrm{u}}+\mathrm{IMF}_{2 \mathrm{u}}+\cdots+\mathrm{IMF}_{n \mathrm{u}}+r(t)_{n \mathrm{u}},\right. \\
& H(t)_{\mathrm{d}}=\left\{\mathrm{IMF}_{\mathrm{d}}=\mathrm{IMF}_{1 \mathrm{~d}}+\mathrm{IMF}_{2 \mathrm{~d}}+\cdots+\mathrm{IMF}_{n \mathrm{~d}}+r(t)_{n \mathrm{~d}},\right.
\end{aligned}
$$

where $H(t)_{\mathrm{u}}$ and $H(t)_{\mathrm{d}}$ are the virtual impulse response functions of responses to the undamaged structure and inservice one, respectively; $\{\mathrm{IMF}\}_{\mathrm{u}}$ and $\{\mathrm{IMF}\}_{\mathrm{d}}$ are the intrinsic mode functions of the $H(t)_{\mathrm{u}}$ and $H(t)_{\mathrm{d}}$, respectively; $r(t)_{n \mathrm{u}}$ and $r(t)_{n \mathrm{~d}}$ are residual functions after the empirical mode composition of $H(t)_{\mathrm{u}}$ and $H(t)_{\mathrm{d}}$, respectively; and $n$ is the order of empirical mode decomposition [26, 28].

Because the value of $r(t)_{n \mathrm{u}}$ and $r(t)_{n \mathrm{~d}}$ is much less, $r(t)_{n \mathrm{u}}$ and $r(t)_{n \mathrm{~d}}$ can be neglected. Thus, $H(t)_{\mathrm{u}}$ and $H(t)_{\mathrm{d}}$ can be expressed as follows:

$$
\begin{aligned}
& H(t)_{\mathrm{u}}=\{\mathrm{IMF}\}_{\mathrm{u}}=\mathrm{IMF}_{1 \mathrm{u}}+\mathrm{IMF}_{2 \mathrm{u}}+\cdots+\mathrm{IMF}_{n \mathrm{u}}, \\
& H(t)_{\mathrm{d}}=\{\mathrm{IMF}\}_{\mathrm{d}}=\mathrm{IMF}_{1 \mathrm{~d}}+\mathrm{IMF}_{2 \mathrm{~d}}+\cdots+\mathrm{IMF}_{n \mathrm{~d}} .
\end{aligned}
$$

The components of intrinsic mode functions $\mathrm{IMF}_{j \mathrm{u}}$ and $\operatorname{IMF}_{j \mathrm{~d}}(j=1,2, \ldots, n)$ are expressed as follows:

$$
\begin{aligned}
& \operatorname{IMF}_{j \mathrm{u}}=\operatorname{Re}\left[a_{j \mathrm{u}}(t) \cdot e^{i \int \omega_{j \mathrm{u}}(t) \mathrm{d} t}\right], \\
& \operatorname{IMF}_{j \mathrm{~d}}=\operatorname{Re}\left[a_{j \mathrm{~d}}(t) \cdot e^{i \int \omega_{j d}(t) \mathrm{d} t}\right],
\end{aligned}
$$

where $a_{j}(t)$ and $e^{i \int \omega_{j}(t) \mathrm{d} t}$ are the instantaneous amplitude and instantaneous frequency, respectively, $\omega$ is the frequency, and Re means the real part.

Then, the Hilbert spectrums $\mathbf{H}(\omega, t)_{\mathrm{u}}$ and $\mathbf{H}(\omega, t)_{\mathrm{d}}$ were acquired by Hilbert transformation of the intrinsic mode functions $\{\mathrm{IMF}\}_{\mathrm{u}}$ and $\{\mathrm{IMF}\}_{\mathrm{d}}$. 


$$
\begin{aligned}
& \mathbf{H}(\omega, t)_{\mathrm{u}}=\left\{H\left(\omega_{j}, t\right)\right\}_{\mathrm{u}}=\operatorname{Re}\left\{\left[a_{1 \mathrm{u}}(t) \cdot e^{i \int \omega_{1 \mathrm{u}}(t) \mathrm{d} t}\right]\left[a_{2 \mathrm{u}}(t) \cdot e^{i \int \omega_{2 \mathrm{u}}(t) \mathrm{d} t}\right] \cdots\left[a_{n \mathrm{u}}(t) \cdot e^{i \int \omega_{n \mathrm{u}}(t) \mathrm{d} t}\right]\right\}^{\mathrm{T}}, \\
& \mathbf{H}(\omega, t)_{\mathrm{u}}=\left\{H\left(\omega_{j}, t\right)\right\}_{\mathrm{d}}=\operatorname{Re}\left\{\left[a_{1 \mathrm{~d}}(t) \cdot e^{i \int \omega_{\mathrm{ld}}(t) \mathrm{d} t}\right]\left[a_{2 \mathrm{~d}}(t) \cdot e^{i \int \omega_{2 \mathrm{~d}}(t) \mathrm{d} t}\right] \cdots\left[a_{n \mathrm{~d}}(t) \cdot e^{i \int \omega_{n \mathrm{~d}}(t) \mathrm{d} t}\right]\right\}^{\mathrm{T}},
\end{aligned}
$$

where $\mathbf{H}(\omega, t)_{\mathrm{u}}$ and $\mathbf{H}(\omega, t)_{\mathrm{d}}$ are the Hilbert spectrums of $H(t)_{\mathrm{u}}$ and $H(t)_{\mathrm{d}}$, respectively.

Based on the $\mathbf{H}(\omega, t)_{\mathrm{u}}$ and $\mathbf{H}(\omega, t)_{\mathrm{d}}$, the Hilbert marginal energy spectrums $\mathbf{E}(\omega)_{\mathrm{u}}$ and $\mathbf{E}(\omega)_{\mathrm{d}}$ can be expressed as $[29,30]$ :

$$
\begin{aligned}
\mathbf{E}(\omega)_{\mathrm{u}} & =\left[\begin{array}{llll}
\int_{0}^{T} H\left(\omega_{1}^{2}, t\right)_{\mathrm{u}} \mathrm{d} t & \int_{0}^{T} H\left(\omega_{2}^{2}, t\right)_{\mathrm{u}} \mathrm{d} t & \cdots & \int_{0}^{T} H\left(\omega_{n}^{2}, t\right)_{\mathrm{u}} \mathrm{d} t
\end{array}\right]^{\mathrm{T}}, \\
\mathbf{E}(\omega)_{\mathrm{d}} & =\left[\begin{array}{llll}
\int_{0}^{T} H\left(\omega_{1}, t\right)_{\mathrm{d}} \mathrm{d} t & \int_{0}^{T} H\left(\omega_{2}^{2}, t\right)_{\mathrm{d}} \mathrm{d} t & \cdots & \int_{0}^{T} H\left(\omega_{n}^{2}, t\right)_{\mathrm{d}} \mathrm{d} t
\end{array}\right]^{\mathrm{T}},
\end{aligned}
$$

where $\mathbf{E}(\omega)_{\mathrm{u}}$ and $\mathbf{E}(\omega)_{\mathrm{d}}$ are the Hilbert marginal energy spectrums of the $H(t)_{\mathrm{u}}$ and $H(t)_{\mathrm{d}}$, respectively, and $T$ is the time length of the signal.

Then, Hilbert marginal energy ratios $\mathrm{ER}_{j \mathrm{u}}$ and $\mathrm{ER}_{j \mathrm{~d}}(j=$ $1,2, \ldots, n)$ are defined as follows:

$$
\mathrm{ER}_{j \mathrm{u}}=\frac{E_{j \mathrm{u}}}{\sum_{j=1}^{n} E_{j \mathrm{u}}} \times 100, \quad(j=1,2, \ldots, n),
$$

where $E_{j \mathrm{u}}$ is the Hilbert marginal energy of the $H(t)_{\mathrm{u}}$.

$$
\mathrm{ER}_{j \mathrm{~d}}=\frac{E_{j \mathrm{~d}}}{\sum_{j=1}^{n} E_{j \mathrm{~d}}} \times 100, \quad(j=1,2, \ldots, n),
$$

where $E_{j \mathrm{~d}}$ is the Hilbert marginal energy of the $H(t)_{\mathrm{d}}$.

Then, the Hilbert marginal energy ratio spectrums $\mathbf{E R}(\omega)_{\mathrm{u}}$ and $\mathbf{E R}(\omega)_{\mathrm{d}}$ can be expressed as follows:

$$
\begin{aligned}
& \mathbf{E R}(\omega)_{\mathrm{u}}=\left[\begin{array}{llll}
\mathrm{ER}_{1 \mathrm{u}} & \mathrm{ER}_{2 \mathrm{u}} & \cdots & \mathrm{ER}_{n \mathrm{u}}
\end{array}\right]^{\mathrm{T}}, \\
& \mathbf{E R}(\omega)_{\mathrm{d}}=\left[\begin{array}{llll}
\mathrm{ER}_{1 \mathrm{~d}} & \mathrm{ER}_{2 \mathrm{~d}} & \cdots & \mathrm{ER}_{n \mathrm{~d}}
\end{array}\right]^{\mathrm{T}},
\end{aligned}
$$

where $\mathbf{E R}(\omega)_{\mathrm{u}}$ and $\mathbf{E R}(\omega)_{\mathrm{d}}$ are the Hilbert marginal energy ratio spectrums of the $H(t)_{\mathrm{u}}$ and $H(t)_{\mathrm{d}}$, respectively.

Due to the influence of inherent frequencies of the retaining wall, not all the sub-frequency bands, which are acquired via EMD, are sensitive to damages. Only those bands, whose frequencies are close to the ones of the retaining wall, are much more sensitive to damages. To sensitively identify damages within the wall, let $\varepsilon \leq\left|\mathrm{ER}_{i \mathrm{u}}-\mathrm{ER}_{i \mathrm{~d}}\right|(i=1,2, \ldots, n)$, where $\varepsilon$ is a threshold value. Then, the $p(p \leq n)$ bands can be selected from the $n$ bands. These energy ratios of the $p$ bands can be used to reflect damage information. However, the effects of the residual ( $n$ p) sub-bands on damage identification should not be ignored either. Thus, the $(n-p)$ sub-bands are merged into one band, which is called the additional frequency band. Then, the energy ratio of the additional frequency band is defined as $\mathrm{ER}_{p+1} ; \mathrm{ER}_{(p+1) \mathrm{u}}=100-\sum_{q=1}^{p} \mathrm{ER}_{q \mathrm{u}}$ and $\mathrm{ER}_{(p+1) \mathrm{d}}=$ $100-\sum_{q=1}^{p} \mathrm{ER}_{q \mathrm{~d}}$ are the energy ratios of the additional frequency band of the $H(t)_{\mathrm{u}}$ and $H(t)_{\mathrm{d}}$, respectively.
Based on the $(p+1)$ energy ratios, the Hilbert feature vector spectrums $\mathbf{E R V}(\omega)_{\mathbf{u}}$ and $\mathbf{E R V}(\omega)_{\mathrm{d}}$ can be expressed as follows:

$$
\begin{aligned}
& \operatorname{ERV}(\omega)_{\mathrm{u}}=\left[\begin{array}{lllll}
\operatorname{ERV}_{1 \mathrm{u}} & \operatorname{ERV}_{2 \mathrm{u}} & \cdots & \operatorname{ERV}_{p \mathrm{u}} & \operatorname{ERV}_{(p+1) \mathrm{u}}
\end{array}\right]^{\mathrm{T}}, \\
& \operatorname{ERV}(\omega)_{\mathrm{d}}=\left[\begin{array}{lllll}
\operatorname{ERV}_{1 \mathrm{~d}} & \operatorname{ERV}_{2 \mathrm{~d}} & \cdots & \operatorname{ERV}_{p \mathrm{~d}} & \operatorname{ERV}_{(p+1) \mathrm{d}}
\end{array}\right]^{\mathrm{T}},
\end{aligned}
$$

where $\operatorname{ERV}_{k \mathrm{u}}$ and $\operatorname{ERV}_{k \mathrm{~d}}(k=1,2, \ldots, p, p+1)$ are the energy ratios of the $k^{\text {th }}$ frequency band of the $H(t)_{\mathrm{u}}$ and $H(t)_{\mathrm{d}}$, respectively.

On the basis of the $\operatorname{ERV}(\omega)_{\mathbf{u}}$ and $\operatorname{ERV}(\omega)_{\mathbf{d}}$, the Hilbert marginal energy ratio deviation $\operatorname{ERD}(\omega)_{k}$ is calculated:

$$
\operatorname{ERD}(\omega)_{k}=\left|\mathrm{ERV}_{k \mathrm{u}}-\mathrm{ERV}_{k \mathrm{~d}}\right|, \quad(k=1,2, \ldots, p, p+1) .
$$

If the energy ratios in the $\operatorname{ERV}(\omega)_{\mathbf{u}}$ can be regarded as baselines, the energy ratios in the $\operatorname{ERV}(\omega)_{\mathrm{d}}$ fluctuate up and down on the basis of the ones in $\operatorname{ERV}(\omega)_{\mathrm{u}}$ due to damages. To describe the fluctuation intensity of energy ratios, the Hilbert damage feature vector spectrum $\operatorname{ERD}(\omega)$ is acquired and expressed as follows:

$$
\operatorname{ER} \mathbf{D}(\omega)=\left[\begin{array}{lllll}
\mathrm{ERD}_{1} & \mathrm{ERD}_{2} & \cdots & \mathrm{ERD}_{p} & \mathrm{ERD}_{p+1}
\end{array}\right]^{\mathrm{T}} .
$$

The energy ratios in the $\operatorname{ERV}(\omega)_{\mathrm{d}}$ do not change in comparison with the ones in the $\operatorname{ERV}(\omega)_{u}$ when the $\operatorname{ERD}(\omega)=0$. Thus, the retaining wall is not damaged. The energy ratios in the $\operatorname{ERV}(\omega)_{\mathrm{d}}$ fluctuate up and down based on the ones in the $\operatorname{ERV}(\omega)_{\mathbf{u}}$ when the $\operatorname{ERD}(\omega) \neq 0$. Thus, the wall is damaged. So the Hilbert damage feature vector spectrum $\operatorname{ERD}(\omega)$ can be used to detect the damage state of the retaining wall qualitatively.

Based on the $\operatorname{ERD}(\omega)$, the damage identification index ERSD (energy ratio standard deviation) is defined as follows:

$$
\operatorname{ERSD}=\sqrt{\sum_{k=1}^{p+1}\left(\frac{\operatorname{ERD}(\omega)_{k}}{p+1}\right)^{2}} .
$$

$\mathrm{ERSD}=0$ when the $\operatorname{ERD}(\omega)=0$. Thus, the retaining wall is not damaged. $\operatorname{ERSD}>0$ when the $\operatorname{ERD}(\omega) \neq 0$. Thus, the wall is damaged. The value of ERSD becomes larger and larger when the fluctuation intensity of $\operatorname{ERD}(\omega)$ becomes larger and larger. With the increase of the ERSD value, the damage intensity of the wall becomes larger and larger. Thus, the damage index ERSD can be used to detect the damage state of the retaining wall quantitatively. 
Because of the influence of partial damage locations, the damage index values of the different measuring points are different. Generally speaking, the damage index values of the points which are located in the damage area will change suddenly in comparison with other points. Thus, partial damage locations can be detected by variations of identification indexes. Moreover, the damage intensity of partial damage within walls can be identified by establishing a quantitative relationship between the damage intensity and identification index. The damage intensity can be calculated reversely via ERSD, if the quantitative relationship between the damage intensity and damage index is known. Consequently, this damage identification method can be used to identify damages within retaining wall structures. The flowchart of this damage diagnosis method is shown in Figure 2. To verify the feasibility and validity of this damage diagnosis method, model tests and field tests on a pile plate retaining wall are performed.

\section{Model Tests on a Pile Plate Retaining Wall}

A pile plate retaining wall, which is used to verify the feasibility and validity of this damage identification method, is a concrete wall (concrete strength grade is C30), as shown in Figure 3(a). The height of the wall is $2.2 \mathrm{~m}$, the length is $3.0 \mathrm{~m}$, and the thickness is $0.2 \mathrm{~m}$. Foundation of the wall is anchored in backfill, and the anchored depth is $0.6 \mathrm{~m}$. Backfill behind the wall is sand, and soil in front of the wall is miscellaneous fill. Material parameters of the wall and backfill are shown in Table 2.

As mentioned before, the retaining wall has big mass and large volume. Only via applying ambient excitations on the retaining wall, dynamic response signals of the wall can be collected efficiently. The ambient excitations, which include wind loads, seismic loads, blast loads, mechanic vibration lads, dynamic loads of vehicles, and their combinations, have strong randomness and uncontrollability. In the light of literature [31], the ambient excitations can be simulated via applying multipoint random excitations. To simulate ambient excitations, three different experimenters hammer in three different positions on the wall with different types of exciting hammers, as shown in Figure 3(a). Due to the difference of hammers and mutual independence of experimenters, the simulated excitations have much stronger randomness and uncontrollability. Thus, the simulated excitations are much closer to ambient ones.

The test equipment include exciting hammers, sensors, and a signal collecting system. In this paper, the exciting hammers are three types of exciting ones, a DFC-2 hammer, a common one, and a rubber one, as shown in Figures $4(\mathrm{a})-4(\mathrm{c})$. The sensors are $941 \mathrm{~B}$ accelerometers that are used to record acceleration signals. The frequency range of this sensor is $0.17 \sim 100 \mathrm{~Hz}$ and the sensitivity is $0.3\left(\mathrm{~V} \cdot \mathrm{s}^{2} /\right.$ $\mathrm{m})$. These sensors are fixed on the wall by binder, as shown in Figure 4(d). The signal collecting system is the JM3863A wireless vibration test system, as shown in Figure 4(e). The signals collected by the JM3863A wireless vibration test system are transmitted to a computer by the JM1802 gateway, as shown in Figure 4(f).

In this article, the ambient excitations, which are simulated via applying multipoint hammer impulse excitations, are a type of low strain excitations. Under low strain excitations, both the wall and filled soil vibrate mildly. Thus, it is assumed that the filled soil vibrates together with the wall. The additional dynamic effects of the filled soil on the wall can be neglected under low strain excitations. Thus, the filled soil and retaining wall can be regarded as one structure [1]. And the damage identification method is not influenced by the filled soil.

A total of 26 measuring points are assigned on the retaining wall. Points 1 to 25 are calculating points, whereas point 26 is a reference point. The number of sensor measuring points is shown in Figure 3(b). The points from I to VI in Figure 3(b) are exciting points.

Damages will occur and accumulate within the retaining wall due to many causes. From a micro-perspective, these damages are micro-cracks or holes [32]. To simulate the actual damage within the retaining wall, various holes are drilled, as shown in Figure 5. The diameter of a single hole is $0.02 \mathrm{~m}$, and the depth is $0.1 \mathrm{~m}$. All of the holes are drilled in two areas $\{L \in(1.375 \mathrm{~m}, 1.625 \mathrm{~m}), H \in(0.875 \mathrm{~m}, 1.125 \mathrm{~m})\}$ and $\{L \in(1.375 \mathrm{~m}, 1.625 \mathrm{~m}), H \in(1.675 \mathrm{~m}, 1.925 \mathrm{~m})\}$, where $L$ is the length of the retaining wall and $H$ is the height. The damage area $\{L \in(1.375 \mathrm{~m}, 1.625 \mathrm{~m}), H \in(0.875 \mathrm{~m}, 1.125 \mathrm{~m})\}$ is defined as damage 1 , and the damage area $\{L \in(1.375 \mathrm{~m}$, $1.625 \mathrm{~m}), H \in(1.675 \mathrm{~m}, 1.925 \mathrm{~m})\}$ is defined as damage 2 , as shown in Figure 3(b).

To represent the partial damage intensity DI (Damage Intensity), define DI as follows:

$$
\mathrm{DI}=\left(\frac{N \cdot V_{\mathrm{h}}}{V}\right),
$$

where $N$ is the number of holes, $V_{\mathrm{h}}$ is the volume of a single hole, and $V$ is the total volume of the partial area $(V=0.25 \mathrm{~m} \times 0.25 \mathrm{~m} \times 0.1 \mathrm{~m})$.

There are no holes within the wall when DI $=0$. So there is no damage within the wall. With the increase of the number of holes, the partial damage intensity DI increases gradually.

3.1. Identification of the Single Damage within the Retaining Wall. The single damage is simulated in the area $\{L \in(1.375 \mathrm{~m}, 1.625 \mathrm{~m}), H \in(0.875 \mathrm{~m}, 1.125 \mathrm{~m})\}$. The damage intensity of the damage area (damage 1 ) is defined as $\mathrm{DI}_{1}$. Eight damage cases are considered to investigate the damage identification of the retaining wall, as listed in Table 3. Here, case 1 is an undamaged case, whereas cases 2 to 8 are damaged cases.

In the light of damage diagnosis method mentioned above, the damage identification of this retaining wall includes six steps: (1) the virtual impulse response functions of the reference point and calculating points should be obtained; (2) EMD of the virtual impulse response functions is performed to acquire intrinsic mode functions, and HT of the intrinsic mode functions is performed to acquire Hilbert 


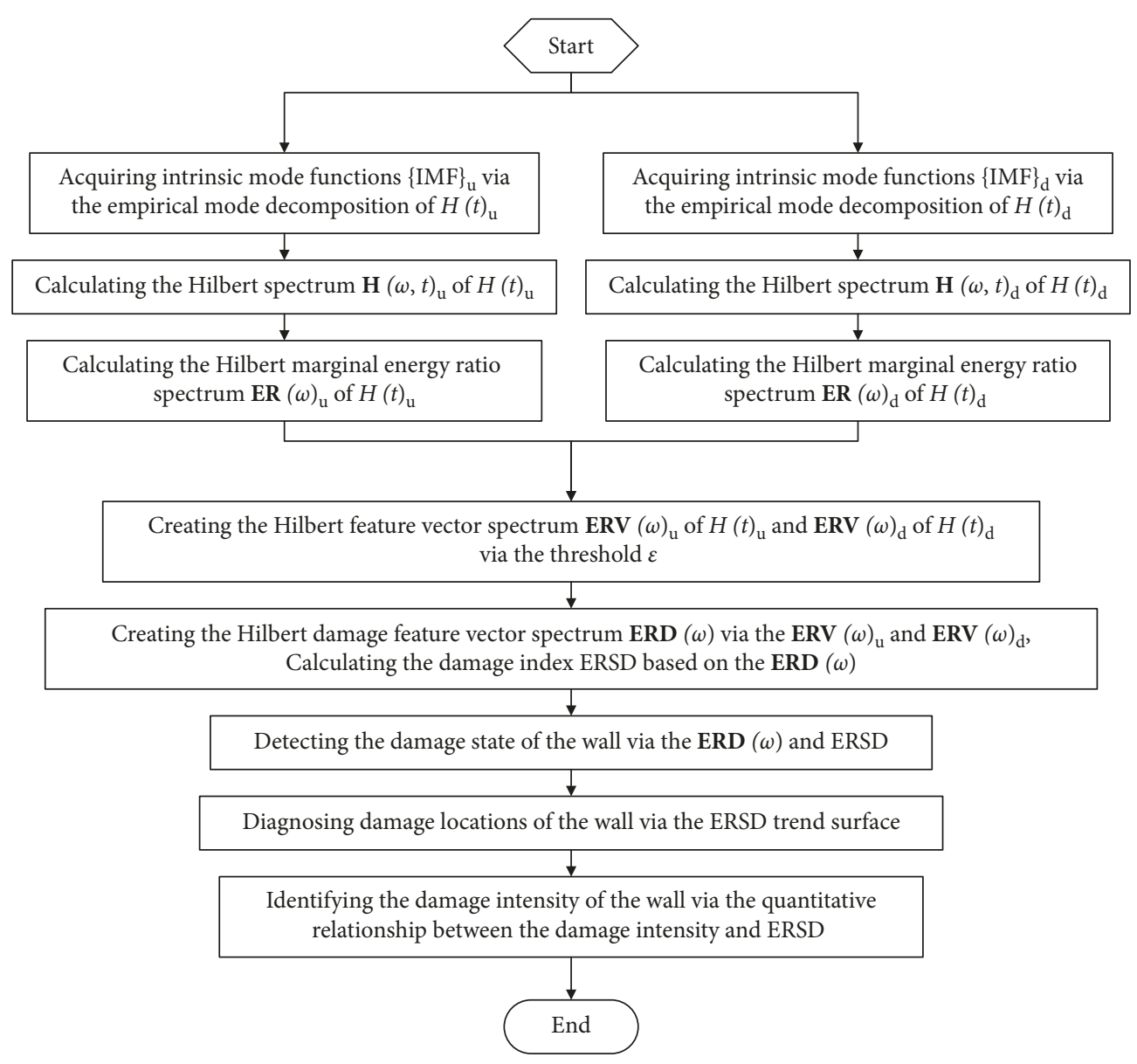

FIGURE 2: Flowchart of damage diagnosis for retaining wall structures.

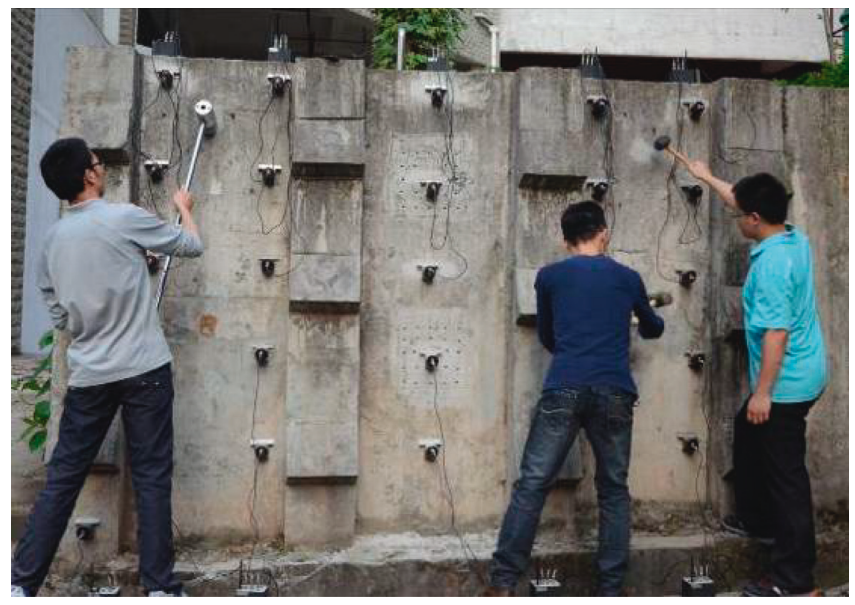

(a)

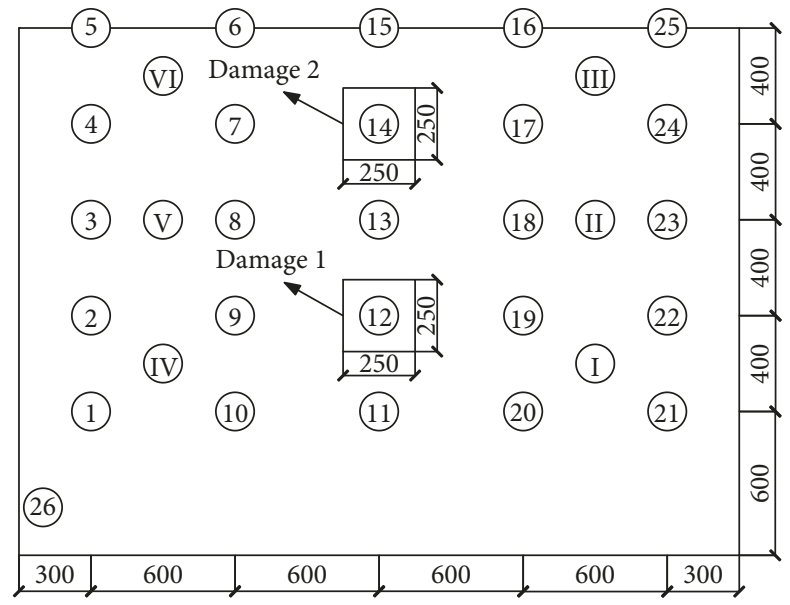

(b)

Figure 3: Pile plate retaining wall in model tests. (a) Vibration tests. (b) Assignment of sensors (unit: mm).

marginal energy spectrum; (3) the Hilbert feature vector spectrum and Hilbert damage feature vector spectrum are created to calculate the damage index; (4) the damage state of the retaining wall is detected; (5) the locations of partial damages within the wall are diagnosed; and (6) the damage intensity of the partial damages is identified.
Under the excitations, the wall is forced to vibrate. The dynamic response signals of measuring points within five minutes are abstracted, as shown in Figure 6. The virtual impulse response functions of the reference point and measuring points are calculated, as shown in Figure 7. In the light of literature [33], the optimum value of EMD order is 
TABLE 2: Material parameters of the concrete and filled soil.

\begin{tabular}{|c|c|c|c|c|c|}
\hline Material & $\begin{array}{l}\text { Density } \\
\left(\mathrm{kg} / \mathrm{m}^{3}\right)\end{array}$ & Elasticity modulus (MPa) & Poisson' ratio & Cohesive force $(\mathrm{kPa})$ & Internal friction angle $\left({ }^{\circ}\right)$ \\
\hline Concrete & 2500 & $2.11 \times 104$ & 0.2 & - & - \\
\hline Filled soil behind the wall & 1901 & 15.4 & 0.3 & 0 & 37.6 \\
\hline Filled soil in front of the wall & 2385 & $2.3 \times 104$ & 0.2 & 460 & 39.5 \\
\hline
\end{tabular}

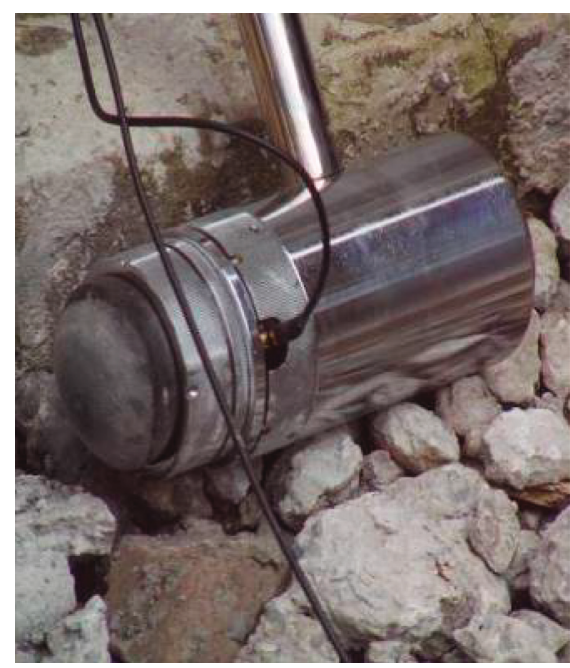

(a)

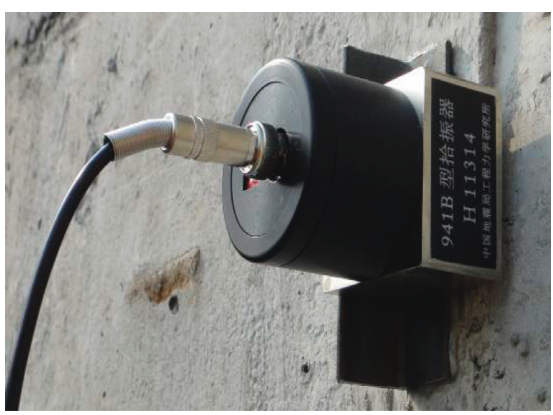

(d)

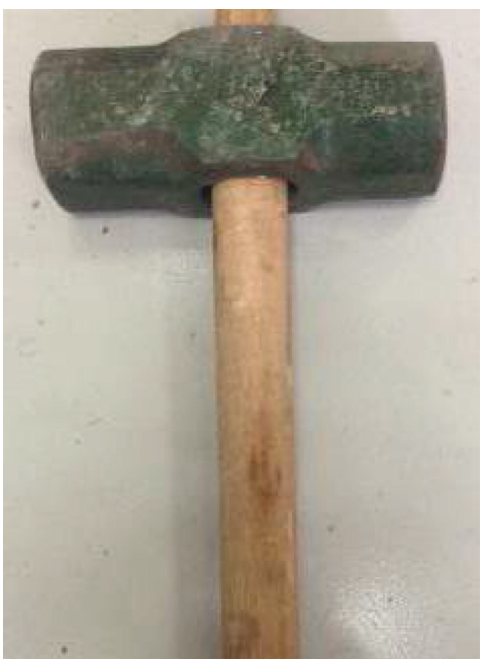

(b)

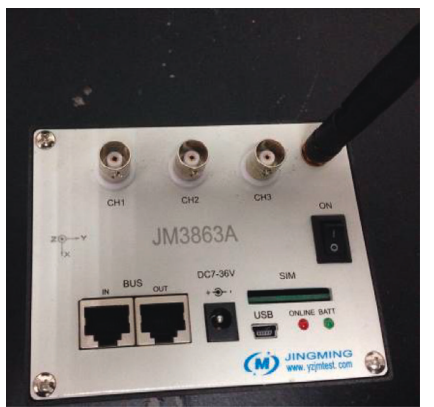

(e)

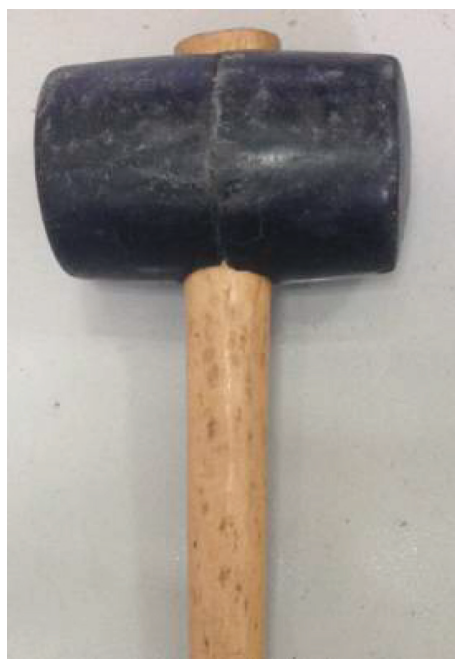

(c)

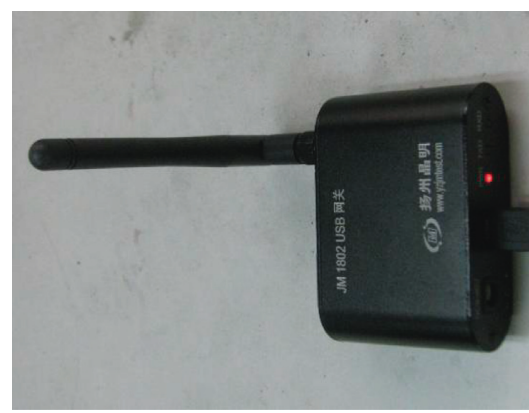

(f)

FIgURE 4: Exciting equipment, sensors, signal collecting system, and signal transmission system of vibration tests. (a) DFC-2 exciting hammer. (b) Common exciting hammer. (c) Rubber exciting hammer. (d) 941B sensor. (e) JM3863A vibration test system. (f) JM1802 wireless gateway.

less than ten, so the value of EMD order is nine. Thus, nine intrinsic mode functions can be acquired via the empirical mode decomposition of a virtual impulse response function, and nine energy ratios of sub-bands can be obtained via HT of the intrinsic mode functions. The Hilbert marginal energy ratio spectrums of the virtual impulse response functions are shown in Figure 8. Due to the influence of the retaining wall with lower frequencies, the majority of sub-band energy is distributed over a minority of bands with lower frequencies. The energy ratio variations caused by damage are nearly undetectable in those bands with higher frequencies that have much less energy. Thus, it is unnecessary to use all of the sub-bands to identify damage.

The energy ratio of the same sub-band changes when the damage occurs in the retaining wall. This variation intensity of the energy ratio can be used to reflect damage state and intensity. However, not only the energy ratio variations of the total frequency bands can be used to reflect damage information but also, via the threshold value $\varepsilon$, those energy ratios, whose variation intensities are much greater, can be used to detect damages. The value of $\varepsilon$ is not constant because the damage sensitivity of each calculating point is different. The value of $\varepsilon$ is much less when the damage sensitivities of the calculating points are much poorer. The value of $\varepsilon$ is much larger when the damage sensitivities of the calculating points are much better. Because the majority of energy ratios are distributed over a minority of sub-bands, energy ratios of the minority bands can be used to replace the Hilbert marginal energy ratio spectrum. Based on the Hilbert marginal energy ratio spectrum and $\varepsilon$, the Hilbert feature vector spectrum is created, as shown in Figure 9. Thus, the Hilbert feature 


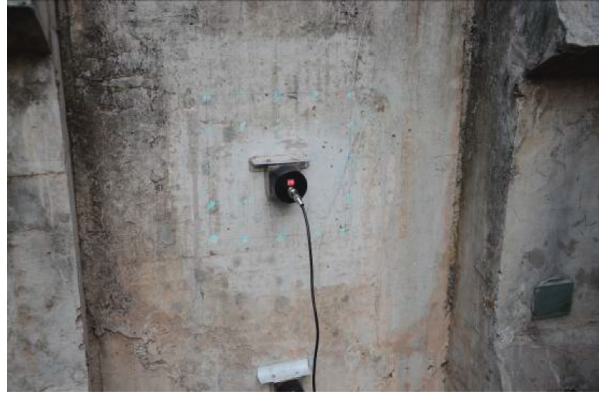

(a)

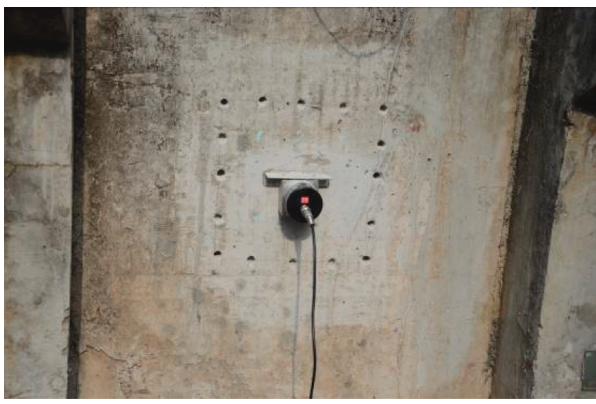

(c)

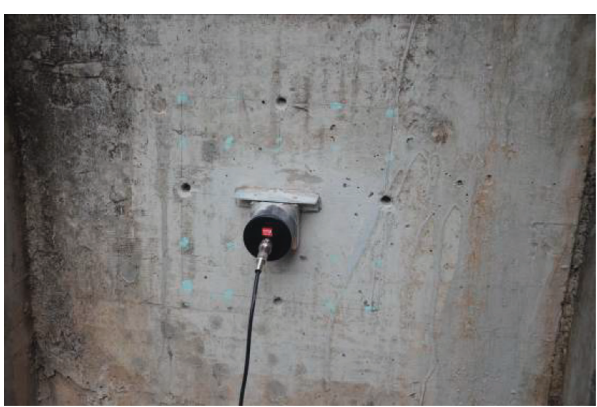

(b)

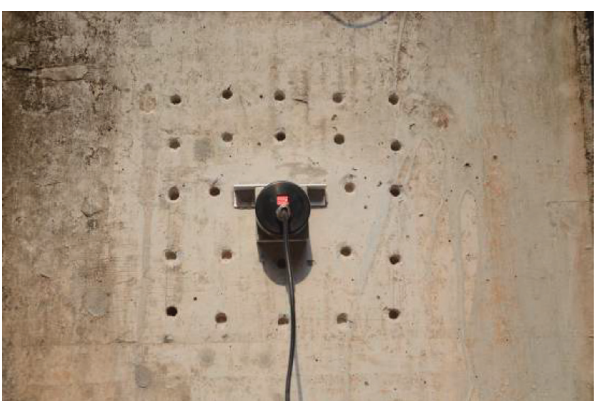

(d)

Figure 5: Partial damage in model tests (single damage). (a) Case 1. (b) Case 3. (c) Case 6. (d) Case 8.

TABle 3: Damage cases in model tests (single damage).

\begin{tabular}{lcccccccc}
\hline Case & Case 1 & Case 2 & Case 3 & Case 4 & Case 5 & Case 6 & Case 7 & Case 8 \\
\hline $\mathrm{DI}_{1}(\%)$ & 0 & 1.00 & 2.01 & 4.02 & 6.03 & 8.04 & 10.05 & 12.06 \\
\hline
\end{tabular}

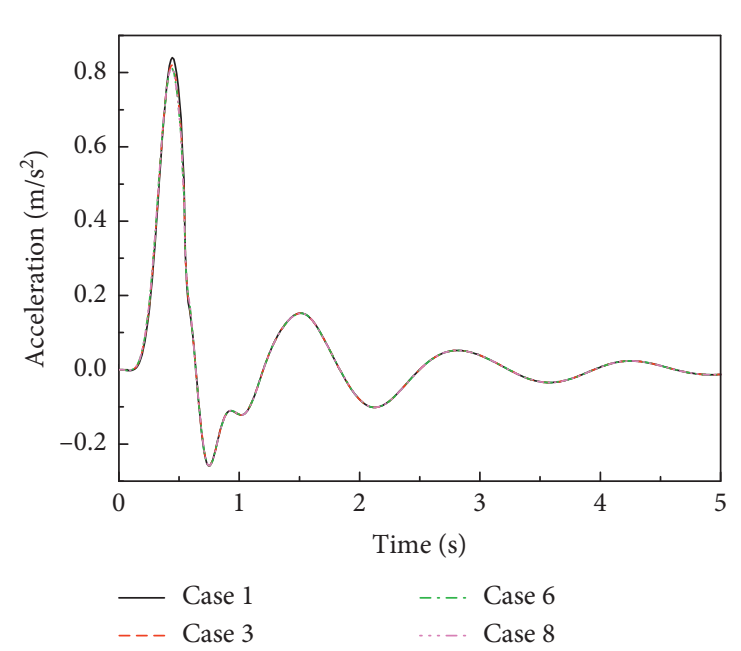

(a)

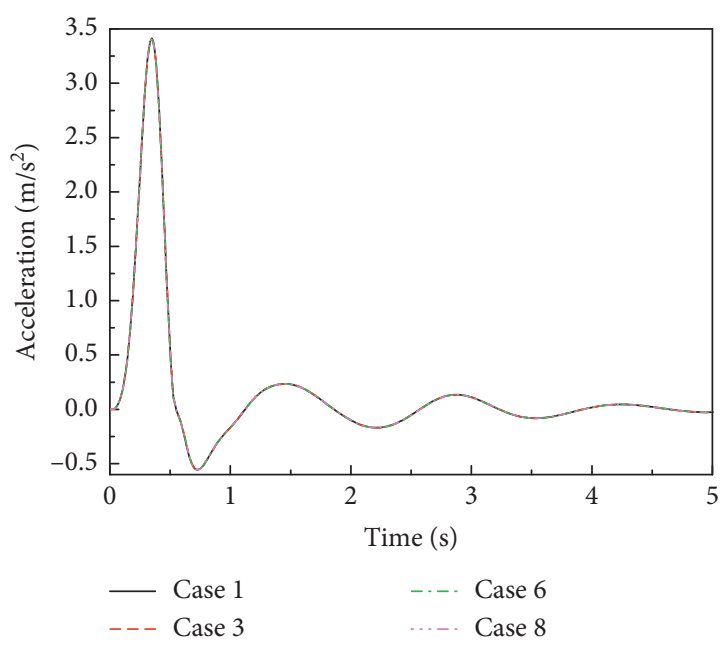

(b)

Figure 6: Continued. 


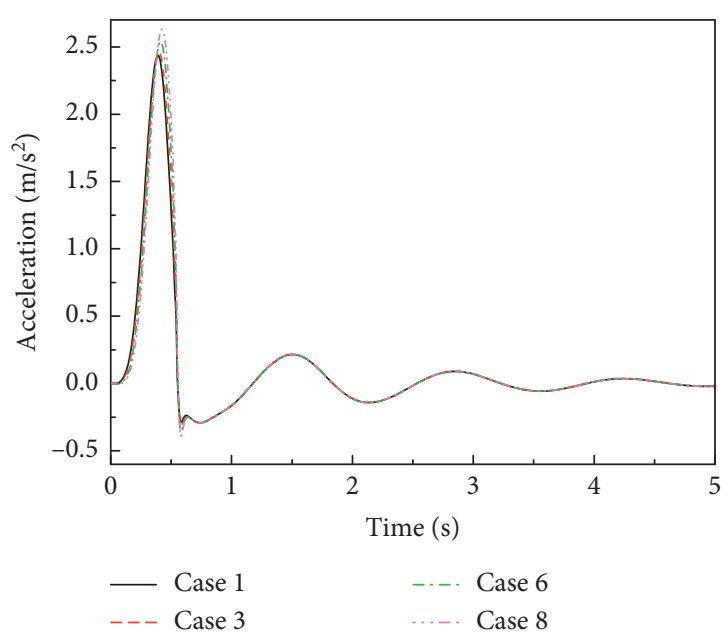

(c)

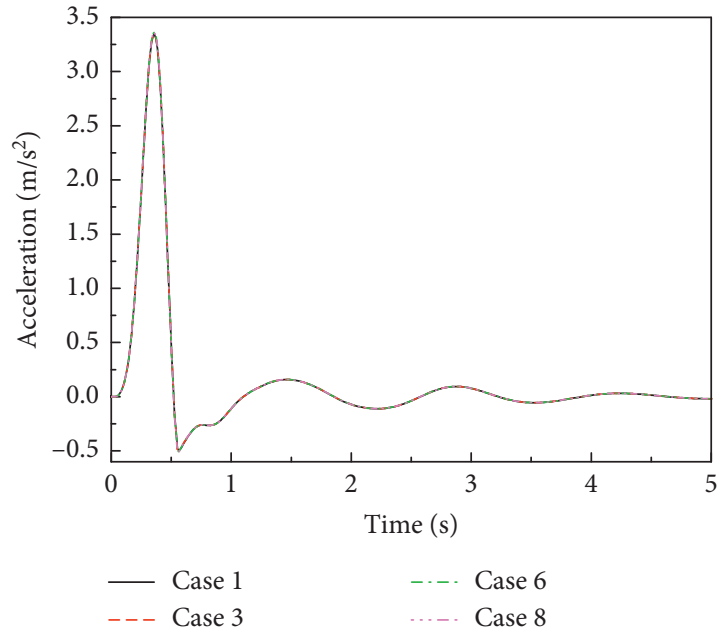

(d)

Figure 6: Acceleration time history curves of measuring points in model tests (single damage). (a) Point 1. (b) Point 7. (c) Point 12. (d) Point 25.

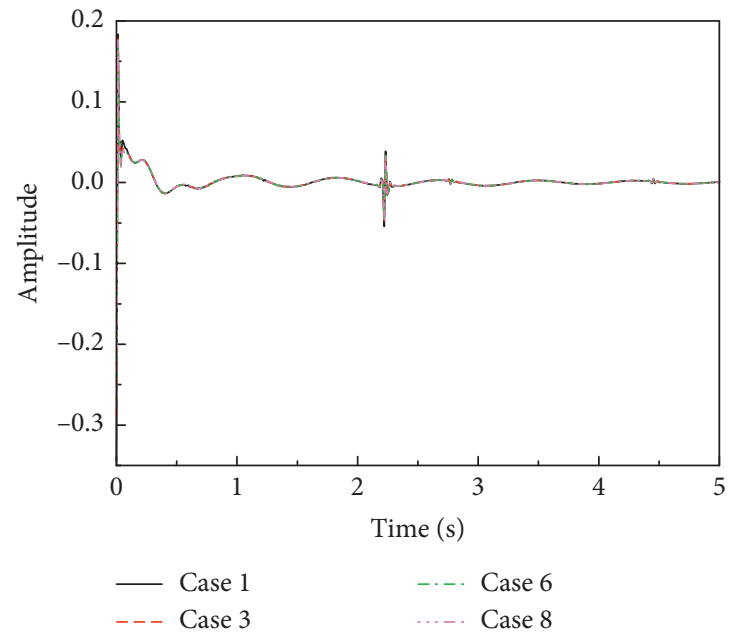

(a)

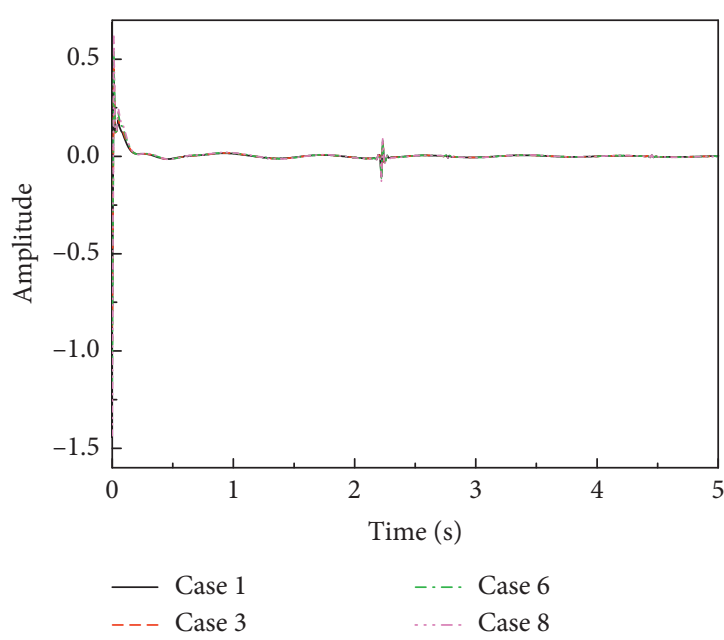

(c)

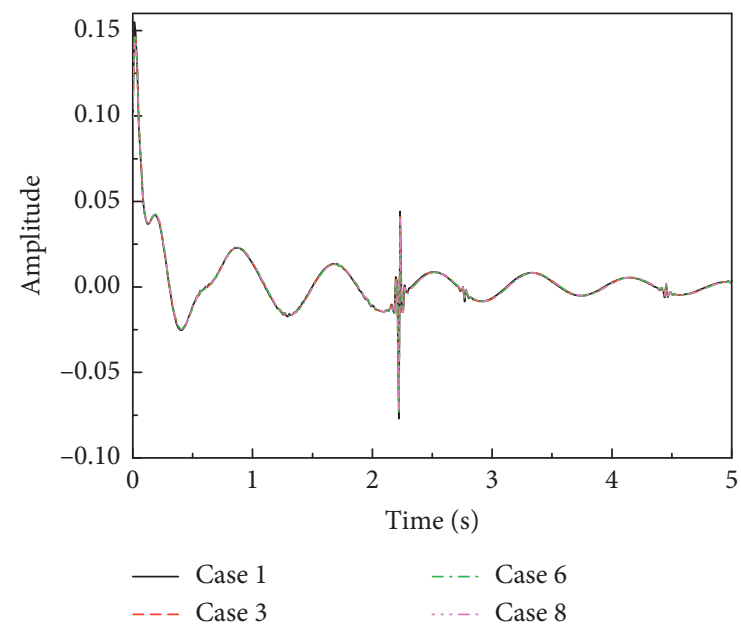

(b)

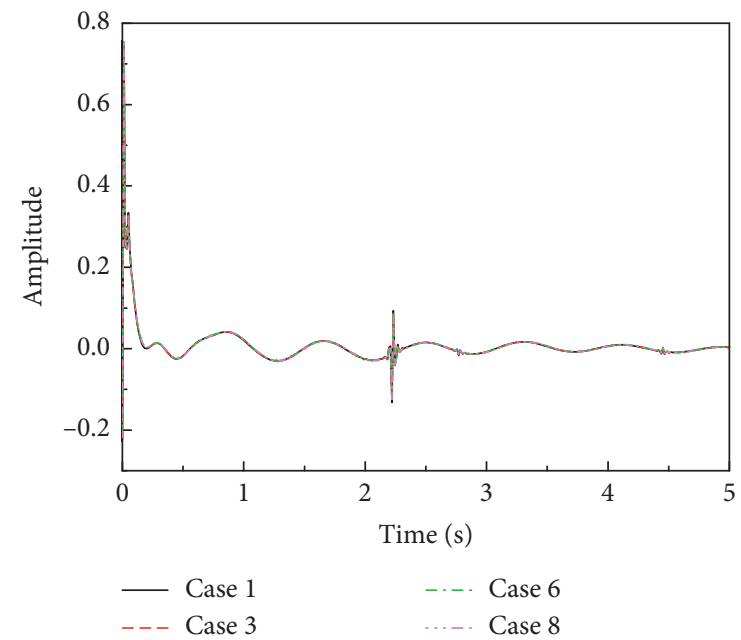

(d)

Figure 7: Virtual impulse response functions of reference point and measuring points in model tests (single damage). (a) Point 1. (b) Point 7. (c) Point 12. (d) Point 25. 


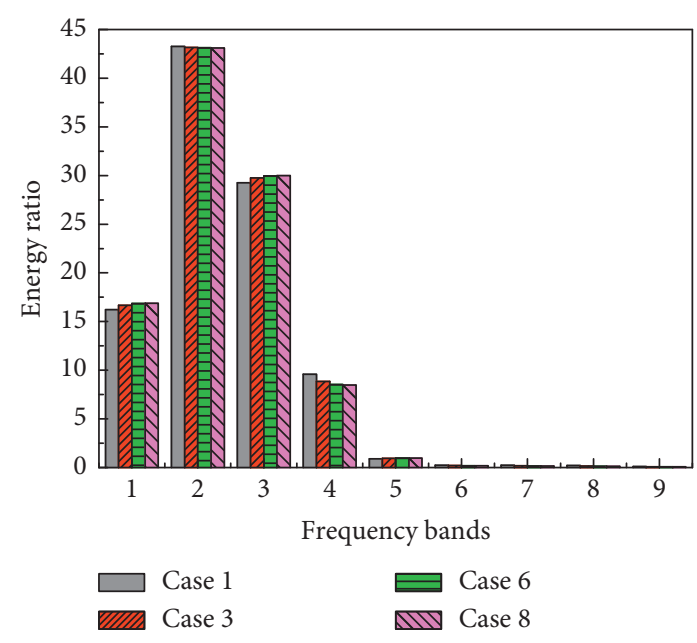

(a)

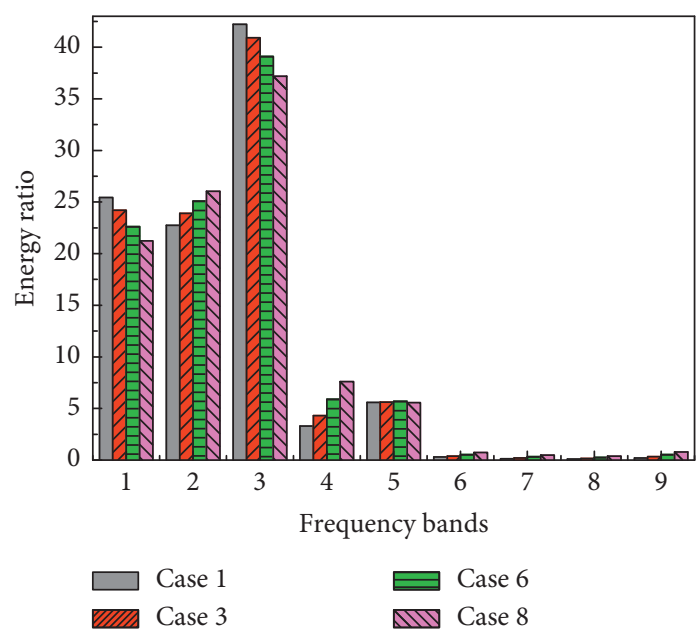

(c)

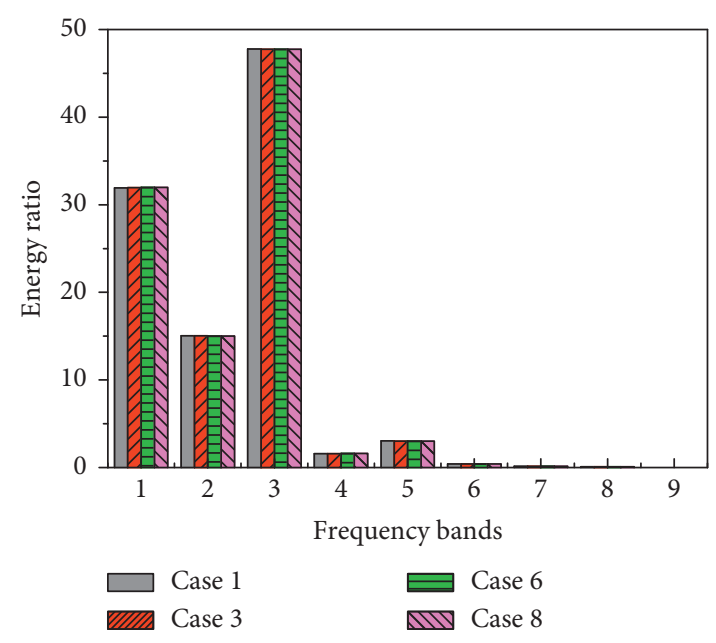

(b)

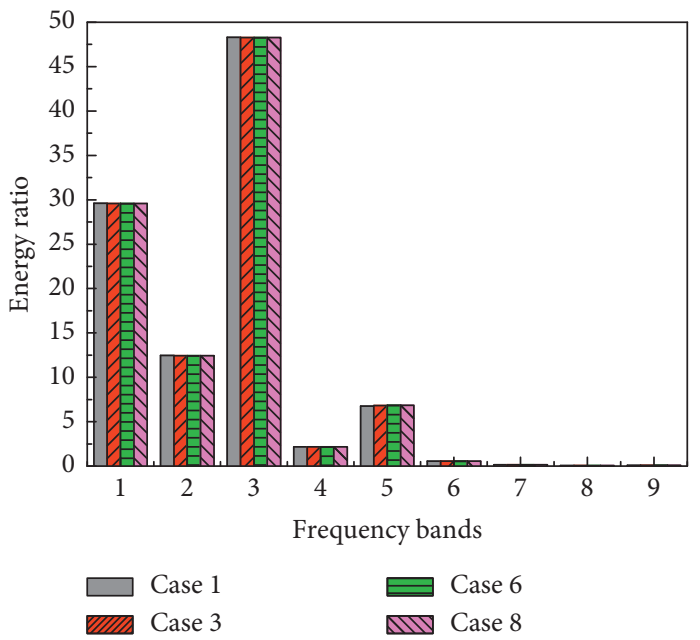

(d)

Figure 8: Hilbert marginal energy ratio spectrum in model tests (single damage). (a) Point 1. (b) Point 7. (c) Point 12. (d) Point 25.

vector spectrum is much more useful in identifying damages within the wall.

Based on the Hilbert feature vector spectrum, the Hilbert damage feature vector spectrum is obtained. With the increase of the drilled holes number, the energy ratio deviation of the frequency band becomes larger and larger, as shown in Figure 10. Due to the influence of the damage location, different points have different sensitivities for the identification of damages. For instance, point 12 has a better ability to identify partial damage within the retaining wall, whereas other points have poorer sensitivities to damage. As mentioned before, the retaining wall is not damaged when the $\operatorname{ERD}(\omega)=0$. The wall is damaged when the $\operatorname{ERD}(\omega) \neq 0$. So the Hilbert damage feature vector spectrum $\operatorname{ERD}(\omega)$ can be used to detect the damage state of the retaining wall qualitatively.

Based on the Hilbert damage feature vector spectrum, the damage index ERSD can be calculated. Under certain damage case, 25 ERSD values are calculated. These 25 ERSD values can be used to form a trend surface by MATLAB program, as shown in Figure 11. The ERSD values change suddenly and reach a peak value in the area $\{L \in(1.375 \mathrm{~m}, 1.625 \mathrm{~m}), H \in(0.875 \mathrm{~m}, 1.125 \mathrm{~m})\}$, where the partial damage (damage 1) is simulated. Thus, the damage location of the retaining wall can be detected accurately by the position of the ERSD peak value on an ERSD trend surface. In the light of the definition of ERSD, the values of ERSD are nonnegative. However, negative values appear in ERSD trend surface. This is caused by MATLAB program.

After diagnosis of the location of partial damage, the damage intensity of partial damage should be identified. The damage intensity $\mathrm{DI}_{1}$ can be identified by obtaining the quantitative relationship between the damage identification index and $\mathrm{DI}_{1}$. The quantitative relationship between $\mathrm{DI}_{1}$ and ERSD (point 12) is fitted by the least squared method, because the single partial damage center is located at point 12. To reduce the degree of polynomial, the relative damage intensity $\mathrm{Di}_{1}$ is defined. Here, $\mathrm{Di}_{1}=\mathrm{DI}_{1} \times 100$. Then, the quantitative relationship between the ERSD and $\mathrm{Di}_{1}$ is fitted. And the quantitative relationship between the ERSD and $\mathrm{Di}_{1}$ can be expressed as follows: 


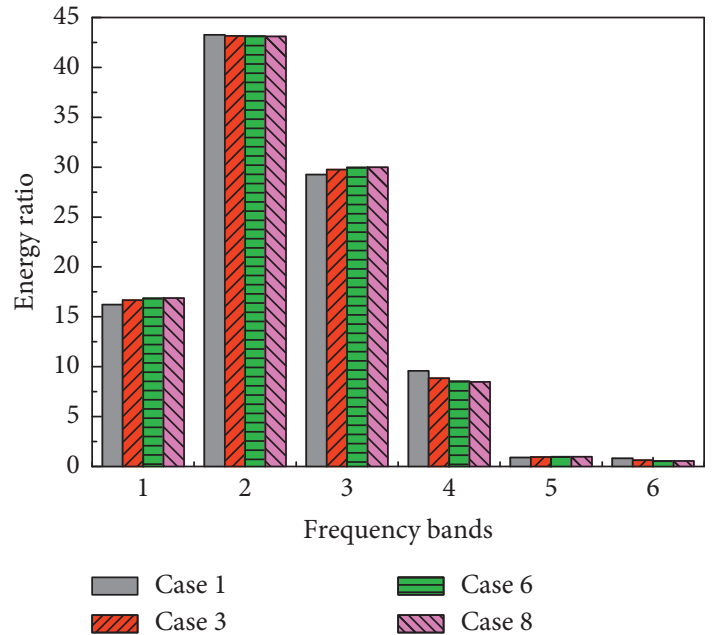

(a)

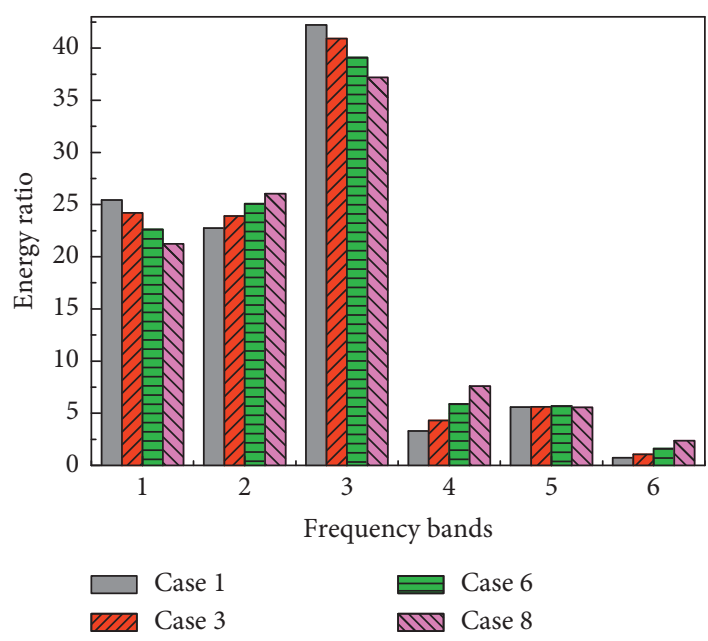

(c)

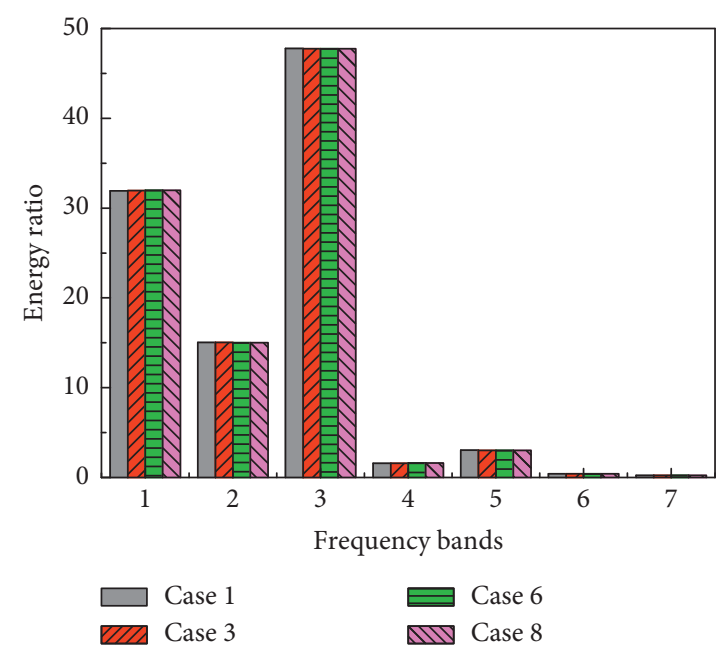

(b)

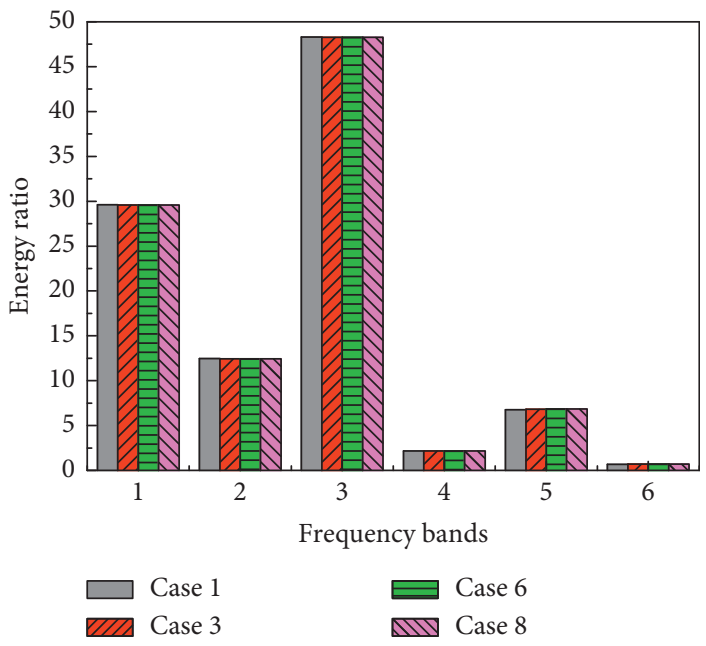

(d)

Figure 9: Hilbert feature vector spectrum in model tests (single damage). (a) Point 1. (b) Point 7. (c) Point 12. (d) Point 25.

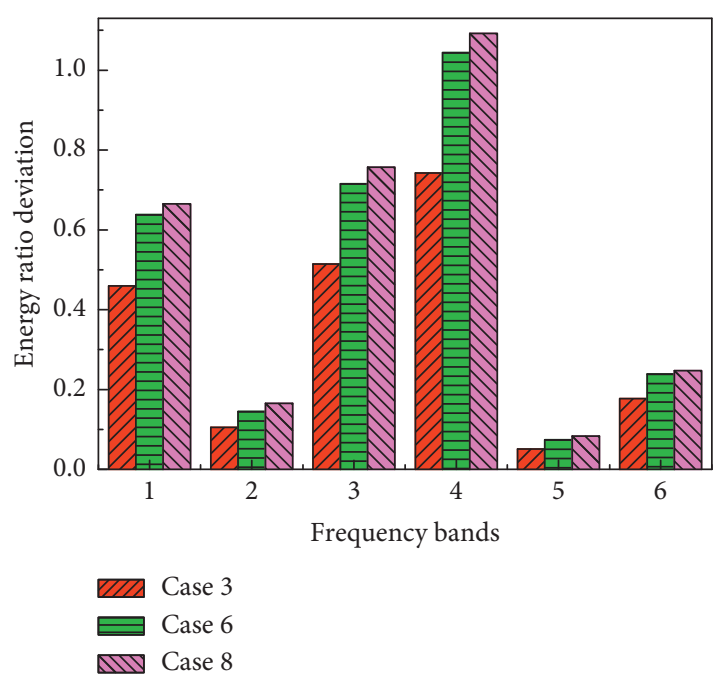

(a)

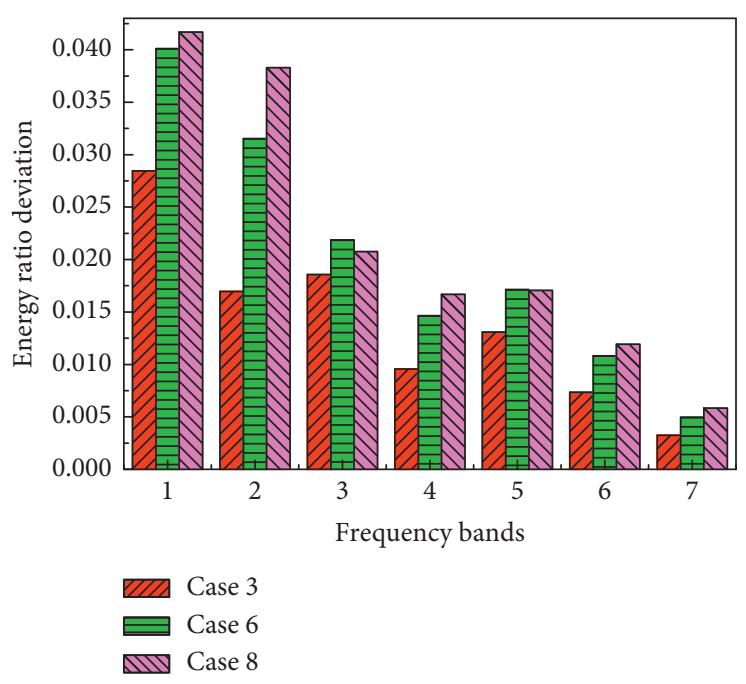

(b)

Figure 10: Continued. 


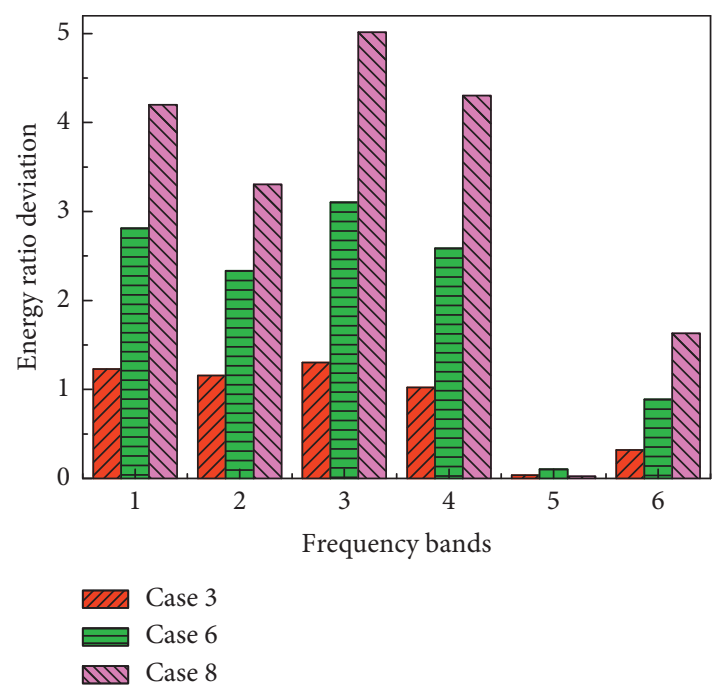

(c)

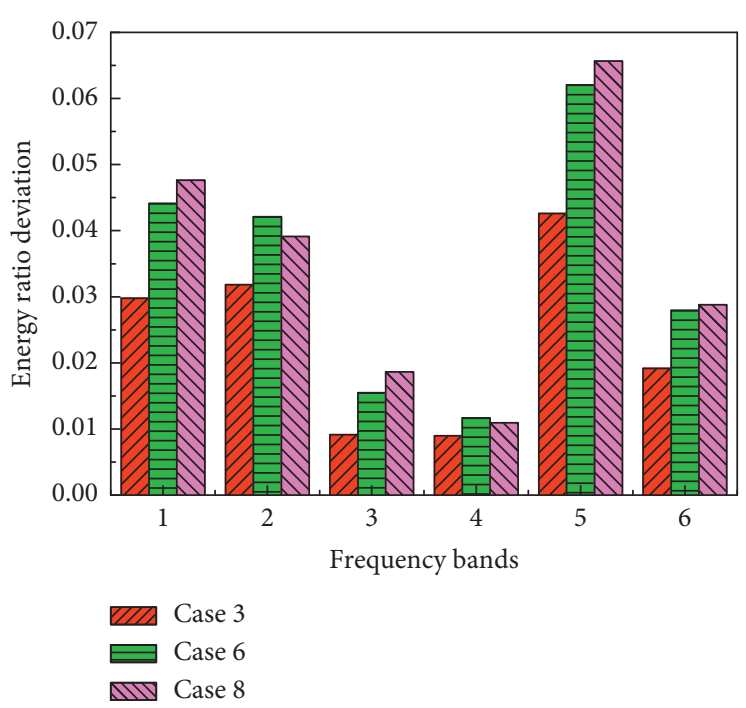

(d)

Figure 10: Hilbert damage feature vector spectrum in model tests (single damage). (a) Point 1. (b) Point 7. (c) Point 12. (d) Point 25.

$$
Y=-0.24 x^{2}+4.61 x+0.07
$$

where $Y$ and $x$ are the relative damage intensity $\mathrm{Di}_{1}$ and ERSD, respectively.

Equation (14) can be expressed as a data-fitting curve. The data-fitting curve and test curve are shown in Figure 12. It is not difficult to verify that these two curves are nearly superpositions. It is believed that equation (14) has a better fitting degree to quantitative relationship between $\mathrm{Di}_{1}$ and the damage identification index. Thus, equation (14) can be used to identify the damage intensity of partial damage within the retaining wall. Once the ERSD is known, the $\mathrm{DI}_{1}$ can be calculated. For instance, $\mathrm{Di}_{1}=4.44$ when $\mathrm{ERSD}=1$. Thus, $\mathrm{DI}_{1}=\mathrm{Di}_{1} / 100=4.44 \%$.

\subsection{Identification of the Two Damages within the Retaining} Wall. The two damages are simulated in the areas $\{L \in(1.375 \mathrm{~m}, \quad 1.625 \mathrm{~m}), \quad H \in(0.875 \mathrm{~m}, 1.125 \mathrm{~m})\} \quad$ and $\{L \in(1.375 \mathrm{~m}, 1.625 \mathrm{~m}), H \in(1.675 \mathrm{~m}, 1.925 \mathrm{~m})\}$. The damage intensity of the damage 2 is defined as $\mathrm{DI}_{2}$. Eight damage cases are considered to investigate the damage identification of the retaining wall, as listed in Table 4 . Here, case 1 is an undamaged case, whereas cases 2 to 8 are damaged cases. In addition, $\mathrm{DI}_{1}$ is constant, whereas $\mathrm{DI}_{2}$ increases gradually from case 2 to case 8, as shown in Figure 13.

Similar to the analysis above, the Hilbert marginal energy spectrum is obtained via EMD and HT. Then, the Hilbert feature vector spectrum and Hilbert damage feature vector spectrum are created and shown in Figures 14 and 15, respectively. With the increase of the holes number, the energy ratio deviation becomes larger and larger, especially the energy ratio deviation of point 14 . Similarly, different points have different sensitivities for the identification of damages. The damage state of the retaining wall can be detected via the Hilbert damage feature vector spectrum $\operatorname{ERD}(\omega)$ sensitively.
As mentioned above, these 25 ERSD values can be used to form a trend surface by MATLAB program, as shown in Figure 16. The ERSD values change suddenly and reach a peak value in the area $\{L \in(1.375 \mathrm{~m}, 1.625 \mathrm{~m}), H \in(0.875 \mathrm{~m}$, $1.125 \mathrm{~m})\}$ and $\{L \in(1.375 \mathrm{~m}, 1.625 \mathrm{~m}), H \in(1.675 \mathrm{~m}$, $1.925 \mathrm{~m}$ ) $\}$, where the partial damages (damage 1 and damage 2) are simulated. Thus, the damage locations of the retaining wall can be detected accurately by the position of the ERSD peak value on an ERSD trend surface.

Because the DI of damage 1 is constant, only the $\mathrm{DI}_{2}$ of damage 2 is identified. The quantitative relationship between the $\mathrm{Di}_{2}$ and ERSD is fitted. And the quantitative relationship between the ERSD and $\mathrm{Di}_{2}$ can be expressed as follows:

$$
Q=-0.18 z^{3}+0.55 z^{2}+3.74 z+0.03
$$

where $Q$ and $z$ are the relative damage intensity $\mathrm{Di}_{2}$ and ERSD, respectively.

Equation (15) can also be expressed as a data-fitting curve. And, the data-fitting curve and test curve are shown in Figure 17. Equation (15) has a better fitting degree to quantitative relationship between the $\mathrm{Di}_{2}$ and ERSD. Thus, equation (15) can be used to identify the damage intensity of partial damage when the quantitative relationship is known. For instance, $\mathrm{Di}_{2}=4.14$ when $\mathrm{ERSD}=1$. Thus, $\mathrm{DI}_{2}=\mathrm{Di}_{2} /$ $100=4.14 \%$.

\section{Field Tests on a Pile Plate Retaining Wall}

A pile plate retaining wall, which is built in January 2016, is in Hechuan district of Chongqing city, China. And the retaining wall is mainly used to retain earth pressure and vehicle loads from the 207 provincial road. The height of the wall is $2.8 \mathrm{~m}$, and the thickness is $0.3 \mathrm{~m}$. The section of the pile is $1 \mathrm{~m} \times 1 \mathrm{~m}$, and the distance between two piles is $4.5 \mathrm{~m}$. Foundation of the wall is anchored in backfill, and the anchored depth is $1.5 \mathrm{~m}$, as shown in Figure 18. The 207 


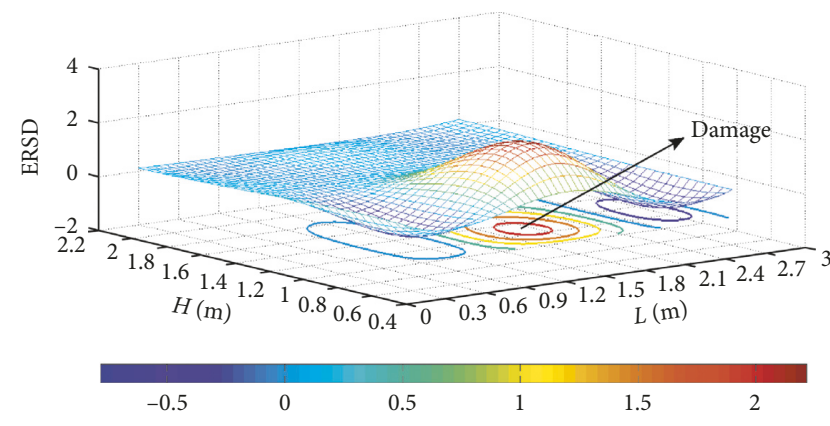

(a)

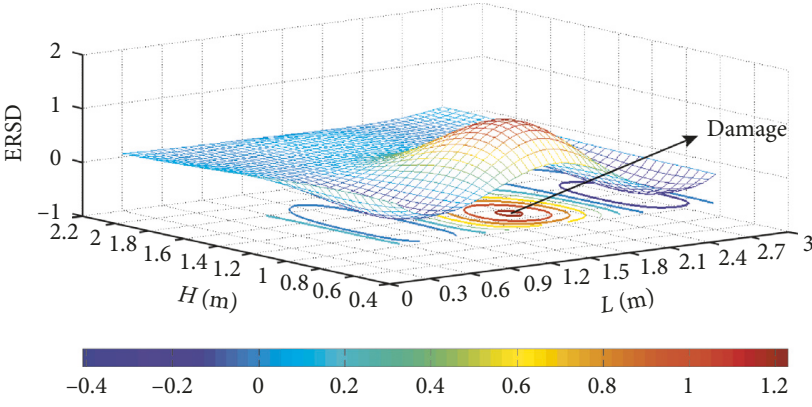

(b)

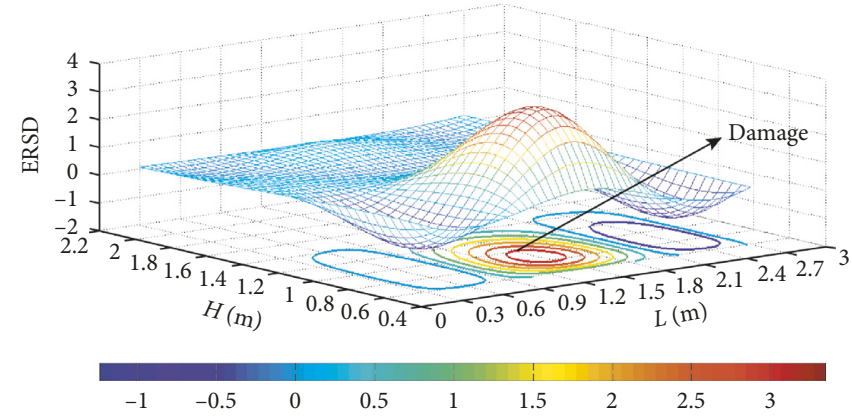

(c)

FIGURE 11: Trend surface of ERSD in model tests (single damage). (a) Case 3. (b) Case 6. (c) Case 8.

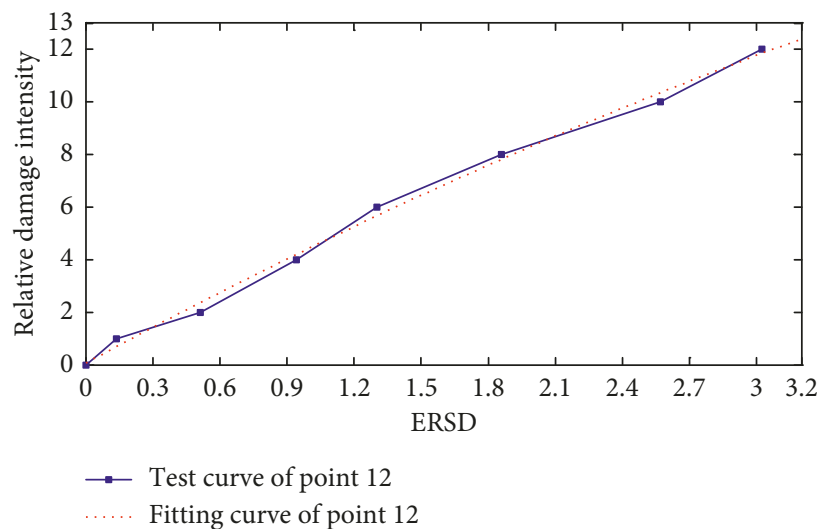

FIGURE 12: Curves of damage intensity and damage index in model tests (single damage).

TABLE 4: Damage cases in model tests (two damages).

\begin{tabular}{lcccccccc}
\hline Case & Case 1 & Case 2 & Case 3 & Case 4 & Case 5 & Case 6 & Case 7 & Case 8 \\
\hline $\mathrm{DI}_{1}(\%)$ & 0 & 12.06 & 12.06 & 12.06 & 12.06 & 12.06 & 12.06 \\
$\mathrm{DI}_{2}(\%)$ & 0 & 1.00 & 2.01 & 4.02 & 6.03 & 8.04 & 12.06 \\
\hline
\end{tabular}

provincial road is behind the wall, and the topography of the wall is shown in Figure 19.

Generally speaking, the first vibration tests on the initial wall should be conducted. The collected data are defined as baseline data. Then, the vibration tests on the inservice wall are performed periodically. And the collected data are defined as operation data. The damage information of the wall can be detected via comparison between the baseline data and operation one. Excitations in tests include artificial excitations and ambient ones. Here, the excitations are ambient excitations caused by vehicles on 207 Provincial road. The first vibration tests on the wall are done on February 5, 2016. The backfill slides in the foundation of the wall due to consistent rainfall in May 2016, which causes many cracks occurring in the backfill. This may cause the wall damaged. To detect the damages within the wall, the vibration tests on the wall are performed for eight times periodically, as listed in Table 5. Due to such limitations as 


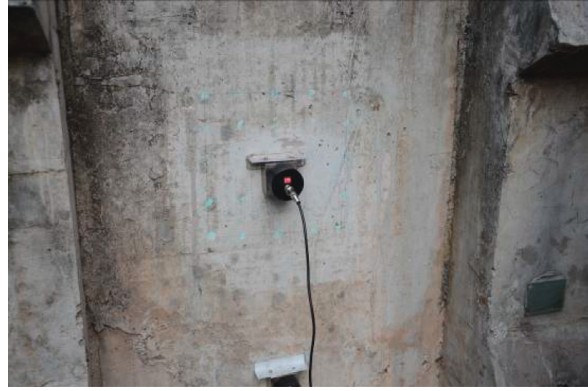

(a)

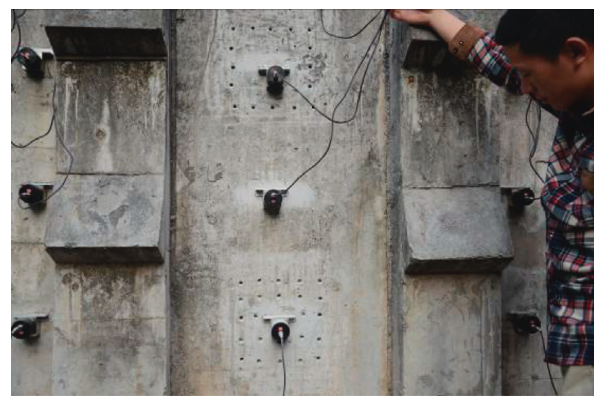

(c)

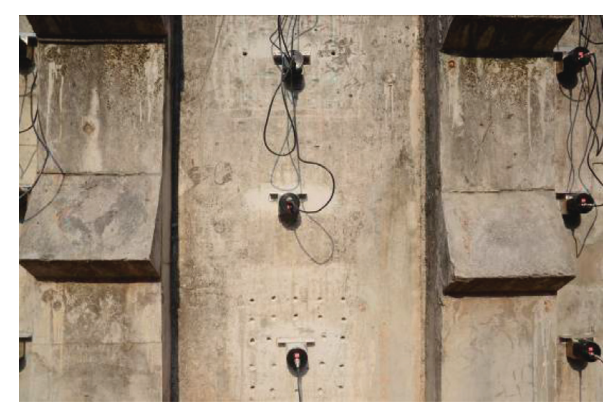

(b)

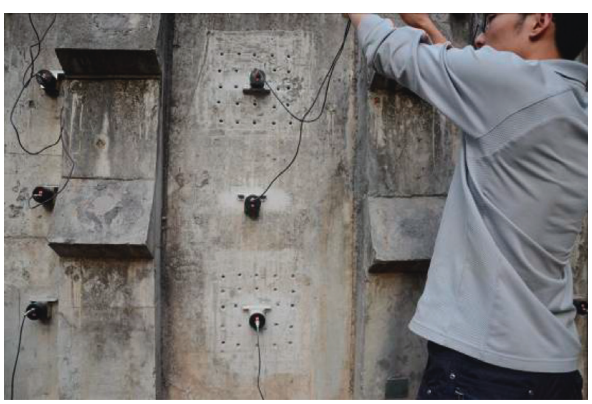

(d)

Figure 13: Partial damages in model tests (two damages). (a) Case 1. (b) Case 3. (c) Case 6. (d) Case 8.

sensor number, sensor location, and the field condition, only 10 points are assigned on the wall to collect dynamic response signals. Points 1 to 9 are calculating points, whereas point 10 is a reference point. The number of sensor measuring points is as shown in Figure 20.

Under the excitations caused by vehicles, the wall is forced to vibrate. The Hilbert marginal energy ratio spectrum can be acquired via HHT of the virtual impulse response functions of the reference point and measuring ones, as shown in Figure 21. Similarly, the majority of signal energy is distributed over the frequency bands with lower frequencies. The total energy in higher frequency bands is about $15 \%$ of the one in total frequency bands. In comparison with the ambient excitations simulated by hammering multipoints, the signal energy is distributed much more evenly under ambient excitations caused by vehicles.

Based on the Hilbert marginal energy ratio spectrum and threshold $\varepsilon$, the Hilbert feature vector spectrum and Hilbert damage feature vector spectrum are acquired, as shown in Figures 22 and 23. The sub-bands with larger energy are sensitive to damages in model tests. In comparison with model tests, not only the frequency bands with larger energy are sensitive to damages but also the frequency bands with less energy are sensitive to damages, such as point 1 and point 12 in Figure 22. From Figure 23, the same results can also be obtained. Additionally, the contributions of the sub-bands with less energy to damage identification are close to the ones of bands with larger energy, such as the point 1 , point 2 , and point 7 . Sometimes, the contributions of the sub-bands with less energy to damage identification are bigger than the ones of bands with larger energy, such as point 5 .

With the increase of time, the values of damage index ERSD increase from February 5, 2016, to June 5, 2016. The values of ERSD are constant from June to July because it is sunny essentially during this time. The values of ERSD increase gradually in August due to the light rain and showers. The values of ERSD increase great due to the rainy season from September to October. The values of ERSD are constant essentially in November and December because of lack of rain, as shown in Figure 24. Thus, rain can accelerate the development of damages within the wall. In addition, rainfall and rain duration have larger effects on damages within the wall. With the increase of rainfall and rain duration, the values of ERSD also increase.

From Figure 23, with the increase of time, it is found that the wall is damaged via the Hilbert damage feature vector under the effects of environment. Due to the sensor number, it is difficult to detect damage location. In addition, it is difficult to define the precise form of damage intensity. For simplicity, the damage intensity DI is defined as DI $=S_{\mathrm{u}} / S_{\mathrm{d}}$, where $S_{\mathrm{u}}$ and $S_{\mathrm{d}}$ are stiffness of the initial wall and inservice wall, respectively. However, the variation characteristics of DI are still unknown. Thus, the damage intensity cannot be identified quantitatively. However, the damage intensity can be identified qualitatively via the variation trend of ERSD. With increase of ERSD, the DI increases and the stiffness of the inservice wall decreases, as shown in Figure 24.

\section{Conclusions}

Regarding the lack of damage identification methods for retaining wall structures, the intrinsic mode functions are acquired via doing the empirical mode decomposition of virtual impulse response functions of responses to the retaining wall under ambient excitations. Then, the Hilbert marginal energy spectrum is obtained by the Hilbert 

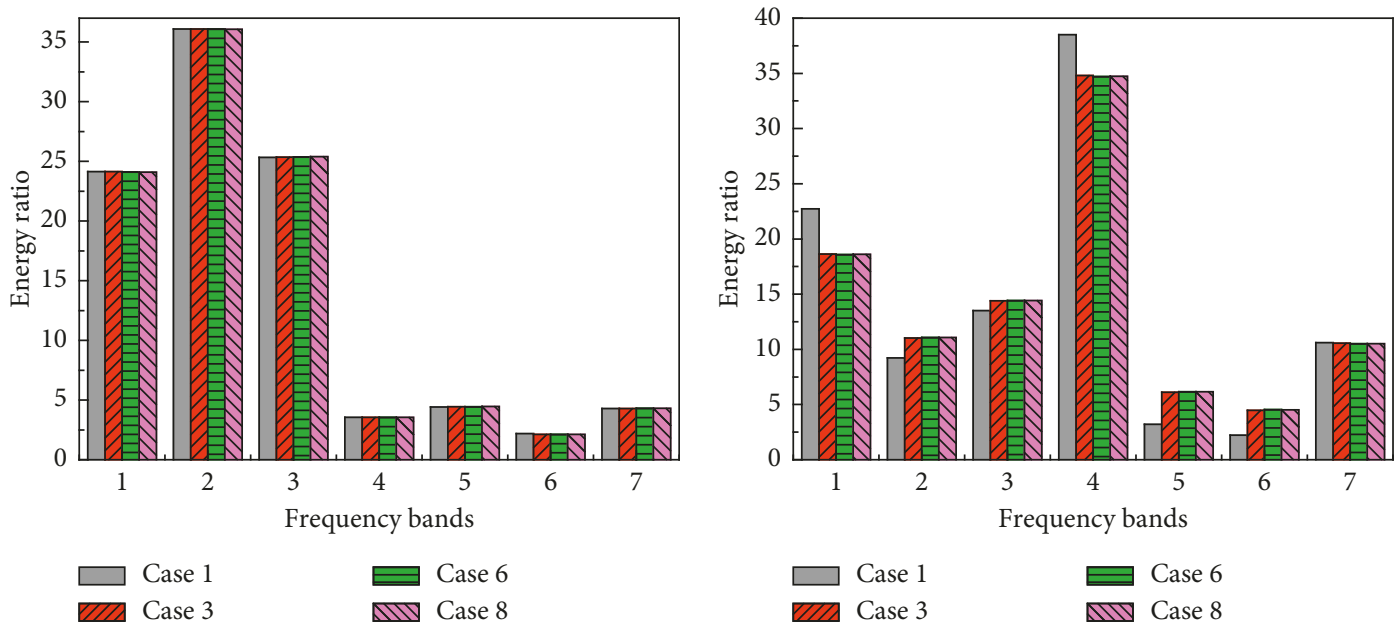

(a)

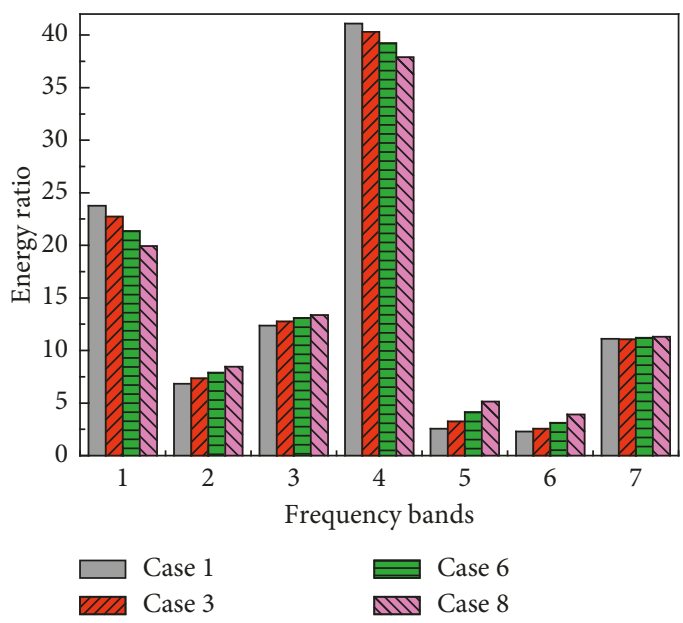

(c)

(b)
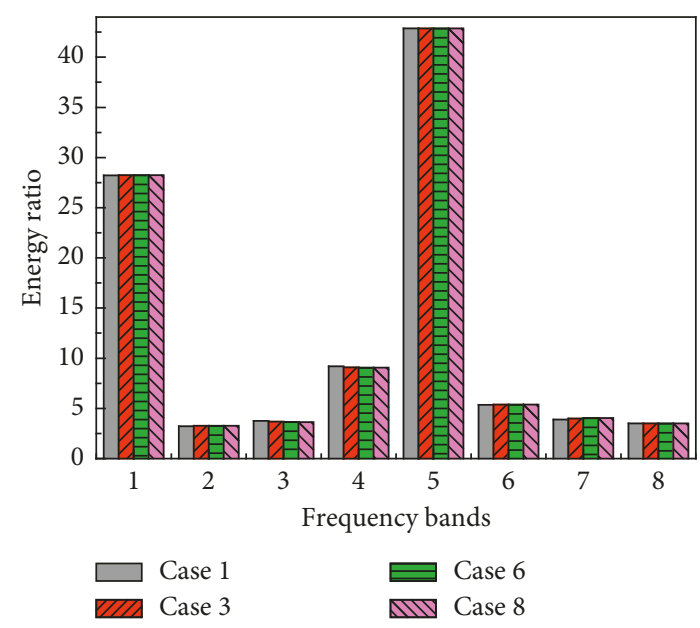

(d)

Figure 14: Hilbert feature vector spectrum in model tests (two damages). (a) Point 1. (b) Point 12. (c) Point 14. (d) Point 25.
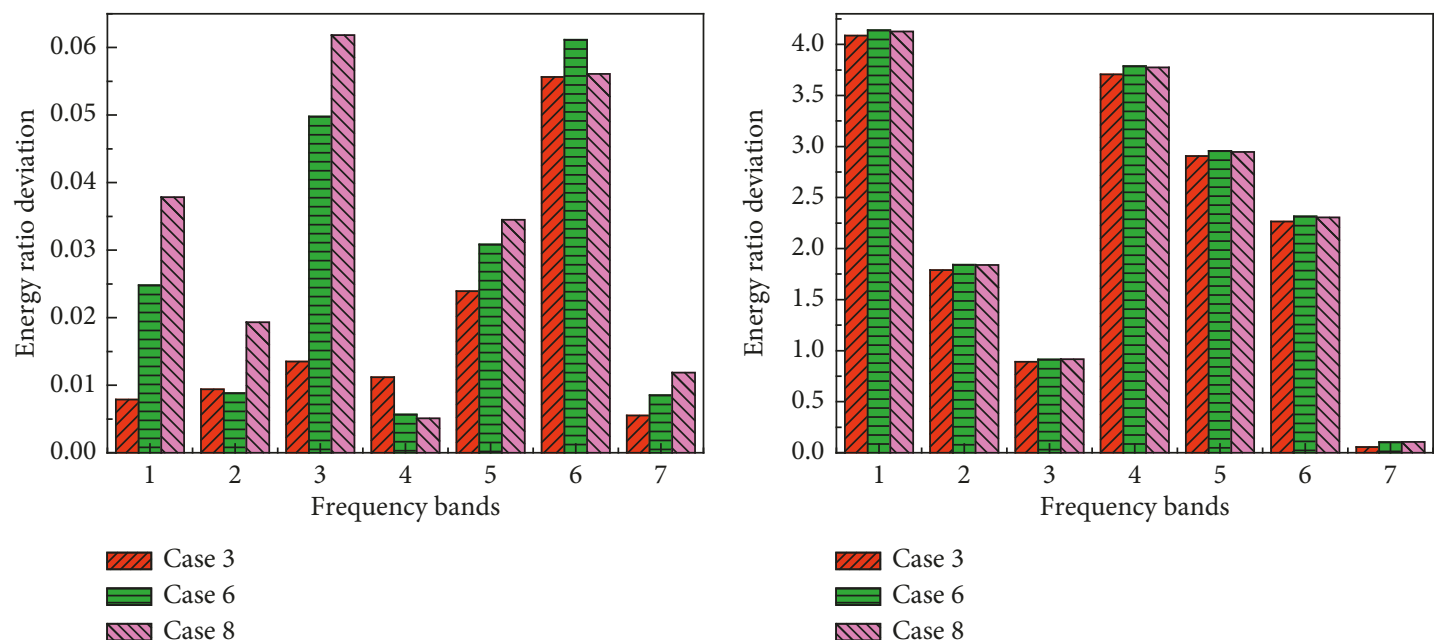

(a)

(b)

FIgURE 15: Continued. 


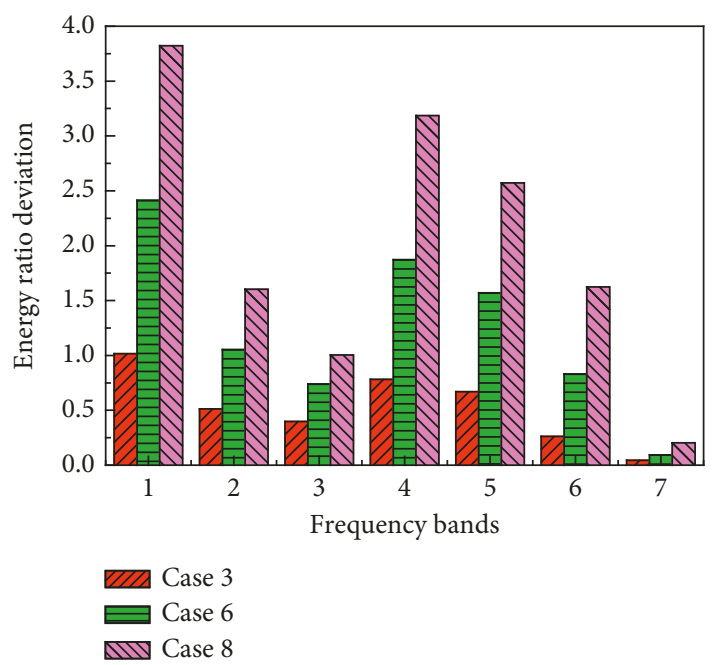

(c)

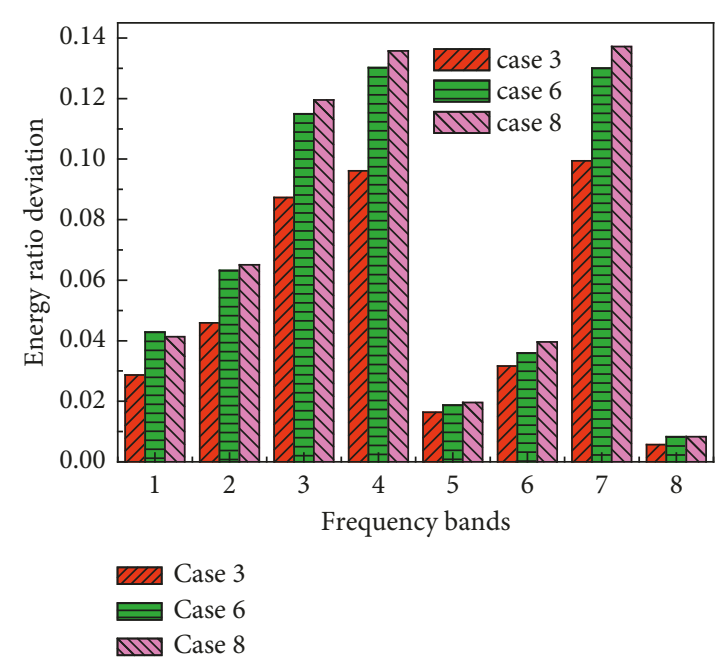

(d)

Figure 15: Hilbert damage feature vector spectrum in model tests (two damages). (a) Point 1. (b) Point 12. (c) Point 14 . (d) Point 25.
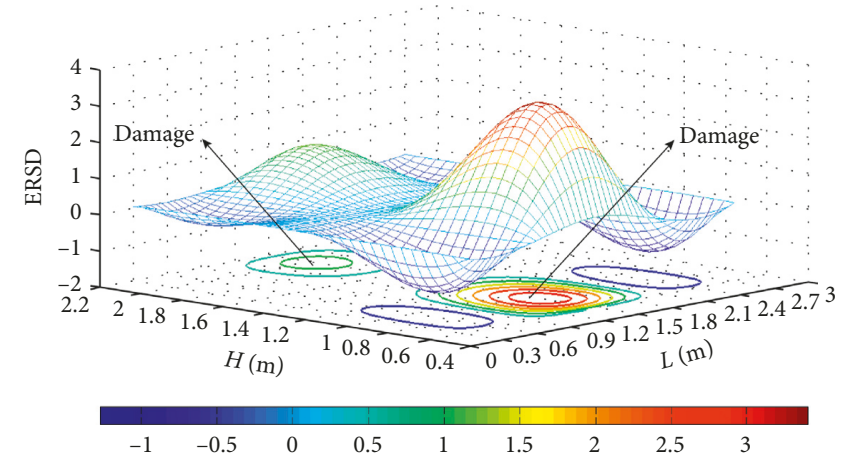

(a)

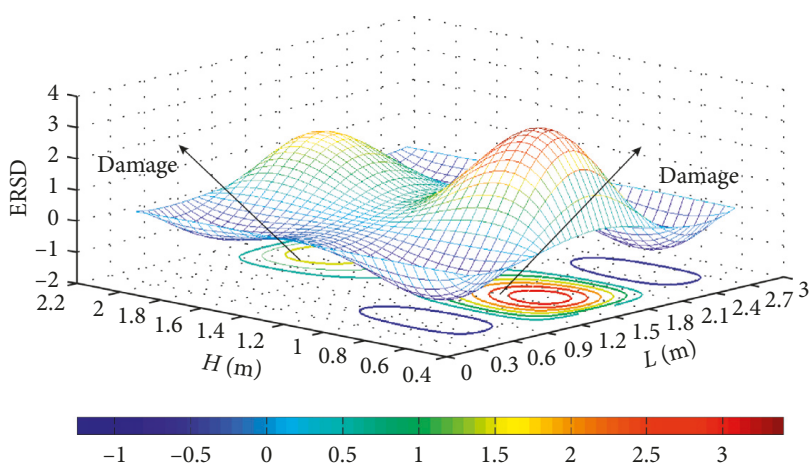

(b)

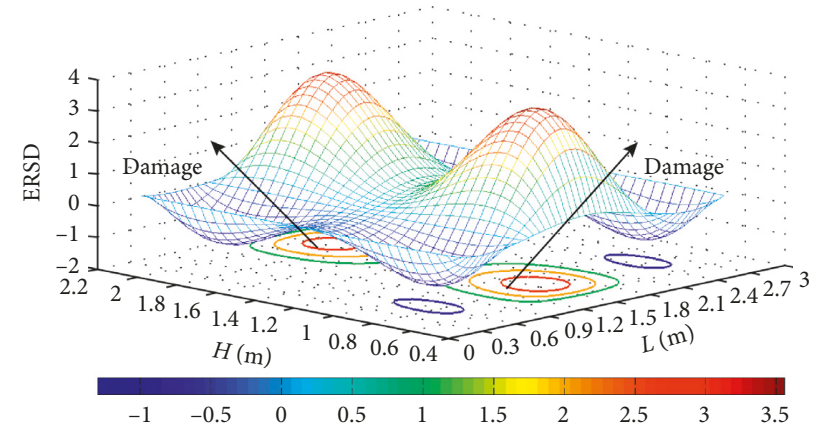

(c)

FIgURE 16: Trend surface of ERSD in model tests (two damages).

transformation of the intrinsic mode functions. Based on the Hilbert marginal energy spectrum, the Hilbert feature vector spectrum and Hilbert damage feature vector spectrum are created. On the basis of the damage feature vector spectrum, a damage index ERSD is proposed. Based on the damage feature vector spectrum and damage index, a damage diagnosis method for retaining wall structures is proposed. The proposed method is verified via the model tests and field tests. Test results show that the damage state of the wall can be detected sensitively, damage locations can be diagnosed validly, and damage intensity can be identified quantitatively via this damage diagnosis method. Although the types of retaining walls are different, the principle of damage identification for retaining walls is the same. Thus, the damages within different types of retaining walls can also be diagnosed by this damage diagnosis method.

In comparison with existing methods for damage identification, this method is not only suitable for retaining 


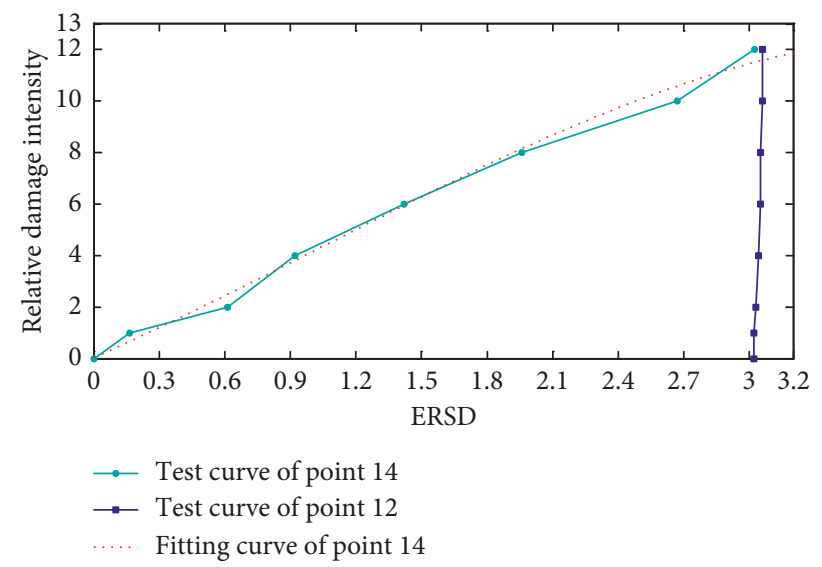

FIGURE 17: Curves of damage intensity and damage index in model tests (two damages).

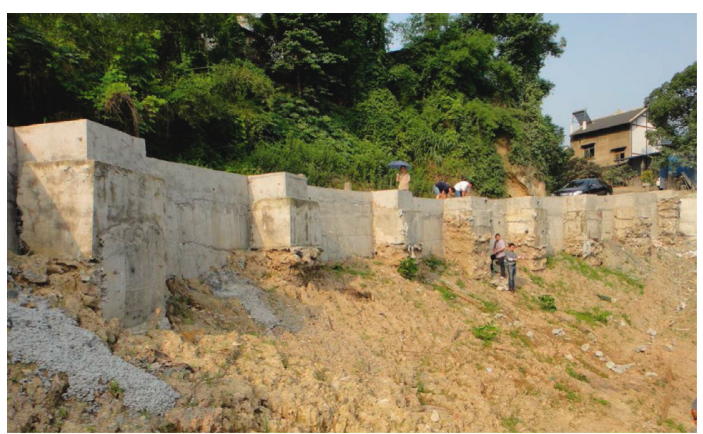

Figure 18: Pile plate retaining wall in field.

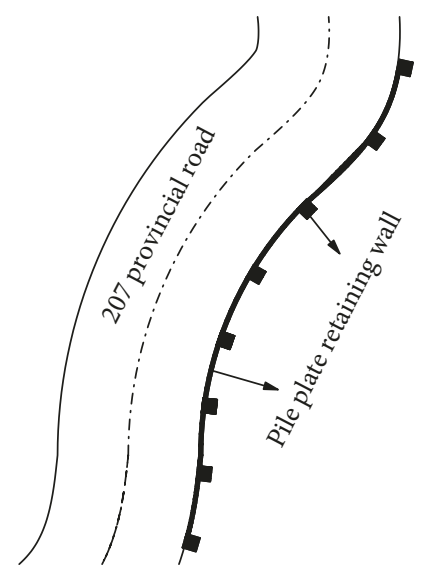

FIGURE 19: Schematic of the topography of the wall.

wall structures but also suitable for such solid-web components or structures as beams, plates, columns, building structures, and bridge structures. However, this method is not suitable for such lattice structures as truss structures, frame ones, and grid ones. In existing methods, the total subbands in the marginal energy spectrum are used to detect damages without considering the sensitivity of sub-bands to damages. However, the Hilbert feature vector spectrum, which is constituted by the $(p+1)$ energy ratios, is much more useful for damage identification. The feature vector spectrum, which replaces the energy ratio spectrum, does not only reflect sensitivities of sub-bands to damages but also considers the contributions of the residual bands to damage identification. Besides, the damage state, damage locations, and damage intensity can be identified via this method. However, it is rare that the damage state, locations, and intensity are all identified by the existing methods. However, there are some faults in this damage diagnosis method.

(1) The retaining wall structure is a system, which is constituted by the wall and backfill. The damages may occur in either the wall or backfill. In this paper, it is assumed that the backfill is undamaged. Only the damages within the wall are identified via the 
TABLE 5: Monitoring records in field tests.

\begin{tabular}{|c|c|c|}
\hline Monitoring number of times & Weather conditions & Remarks \\
\hline $1^{\text {st }}($ on February 5,2016$)$ & Sunny, $9 \sim 14^{\circ} \mathrm{C}$ & \\
\hline $2^{\text {nd }}$ (on June 5,2016 ) & Sunny, $23 \sim 27^{\circ} \mathrm{C}$ & $\begin{array}{c}\text { It is sunny and cloudy in May in the main, and there } \\
\text { is little light rain }\end{array}$ \\
\hline $3^{\text {rd }}$ (on July 5,2016 ) & Sunny, $27 \sim 37^{\circ} \mathrm{C}$ & It is sunny in June in the main, and there is little rain \\
\hline $4^{\text {th }}$ (on August 5,2016$)$ & Sunny, $27 \sim 40^{\circ} \mathrm{C}$ & It is sunny in July in the main, and there is little rain \\
\hline $5^{\text {th }}$ (on September 5,2016$)$ & Cloudy, $22 \sim 36^{\circ} \mathrm{C}$ & $\begin{array}{c}\text { It is sunny and cloudy in August in the main, and } \\
\text { there are little light rain and showers }\end{array}$ \\
\hline $6^{\text {th }}($ on October 5,2016$)$ & Cloudy, $18 \sim 27^{\circ} \mathrm{C}$ & $\begin{array}{l}\text { It rains much more in September, and there are } \\
\text { mainly heavy rains }\end{array}$ \\
\hline $7^{\text {th }}($ on November 5,2016$)$ & Cloudy, $13 \sim 20^{\circ} \mathrm{C}$ & $\begin{array}{c}\text { It rains much more in October, and there are mainly } \\
\text { light to moderate rains }\end{array}$ \\
\hline $8^{\text {th }}($ on December 5,2016$)$ & Cloudy, $9 \sim 14^{\circ} \mathrm{C}$ & $\begin{array}{c}\text { It is cloudy in November in the main, and there is } \\
\text { little rain }\end{array}$ \\
\hline $9^{\text {th }}$ (on January 5,2017 ) & Cloudy, $8 \sim 12^{\circ} \mathrm{C}$ & $\begin{array}{c}\text { It is cloudy in December in the main, and there is } \\
\text { nearly no rain }\end{array}$ \\
\hline
\end{tabular}

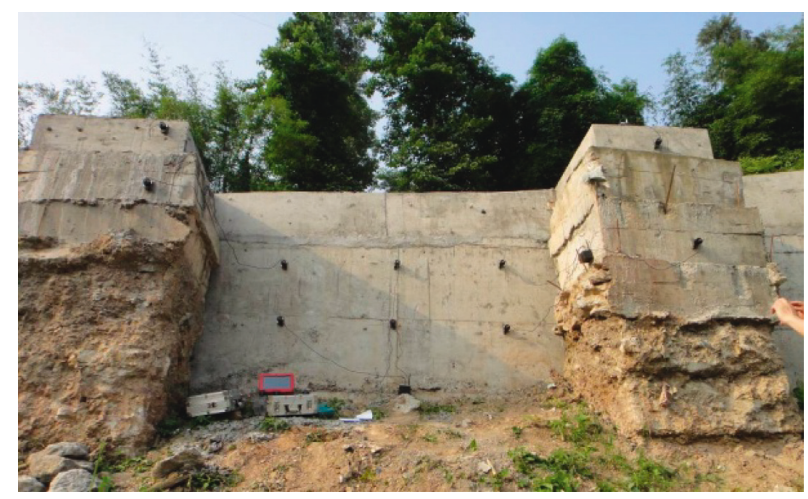

(a)

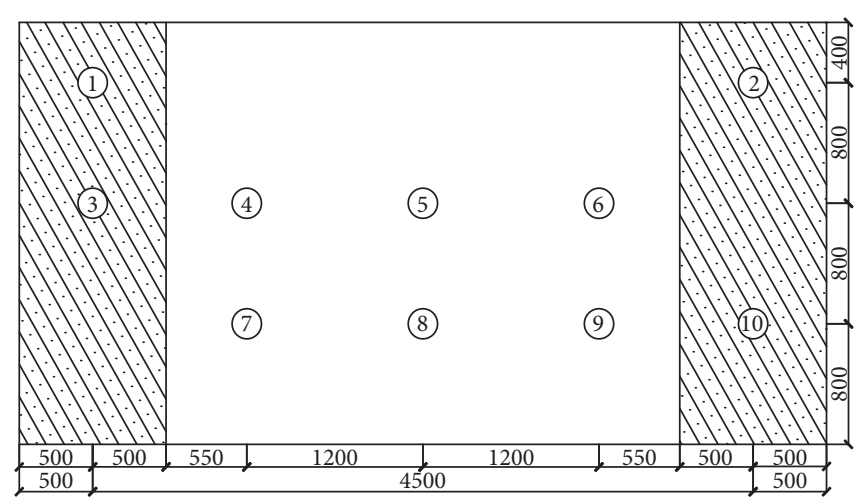

(b)

Figure 20: Pile plate retaining wall in field tests. (a) Vibration tests. (b) Assignment of sensors (unit: mm).

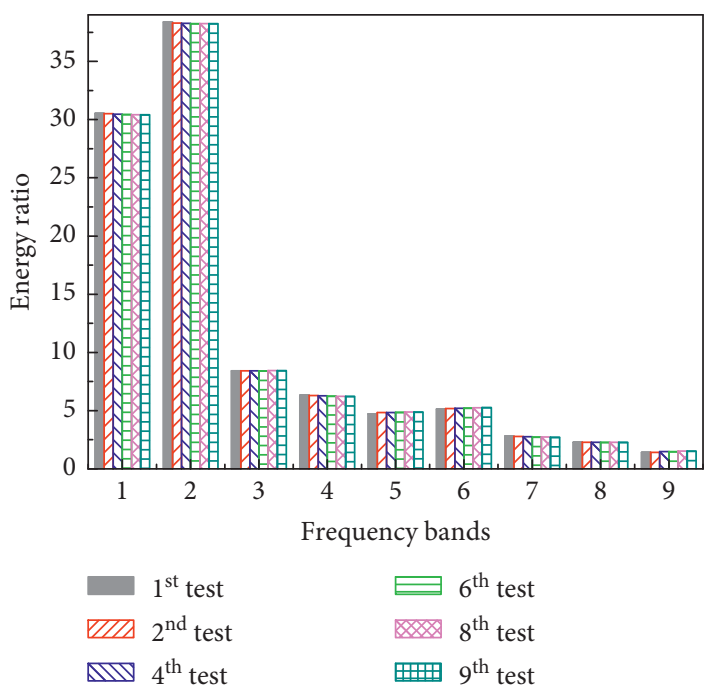

(a)

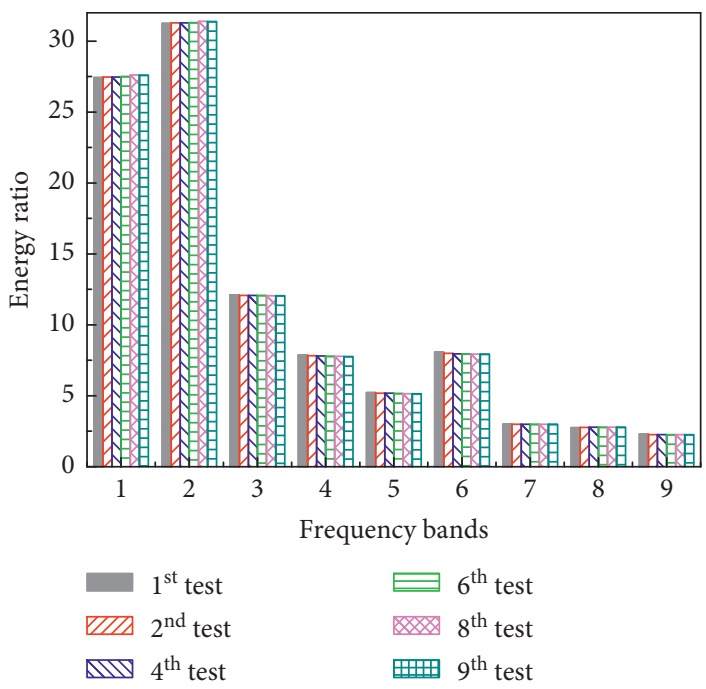

(b)

FIgURE 21: Continued. 


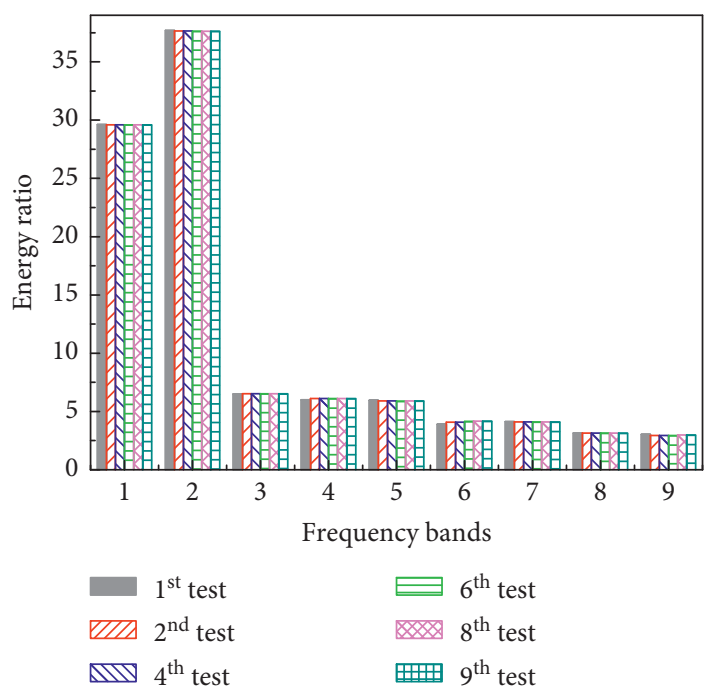

(c)

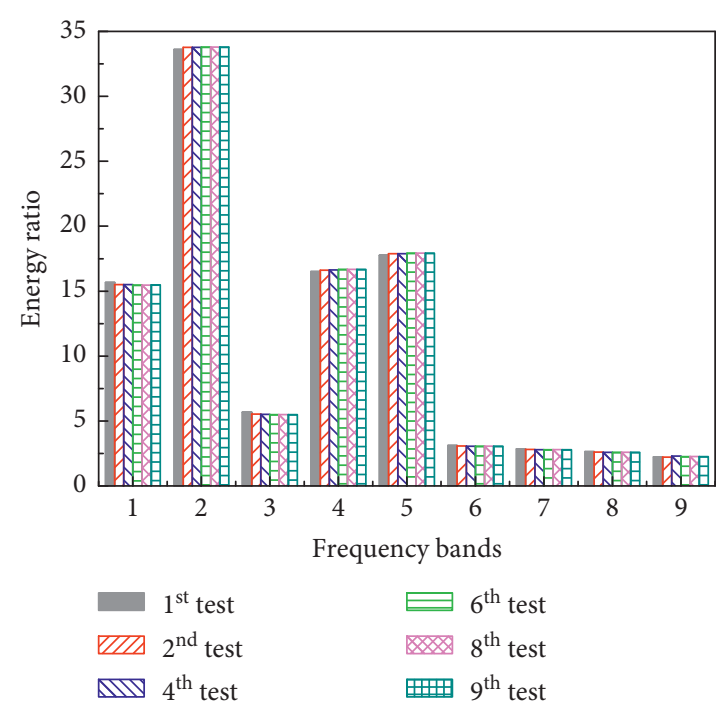

(d)

Figure 21: Hilbert marginal energy ratio spectrum in field tests. (a) Point 1. (b) Point 2. (c) Point 5. (d) Point 7.

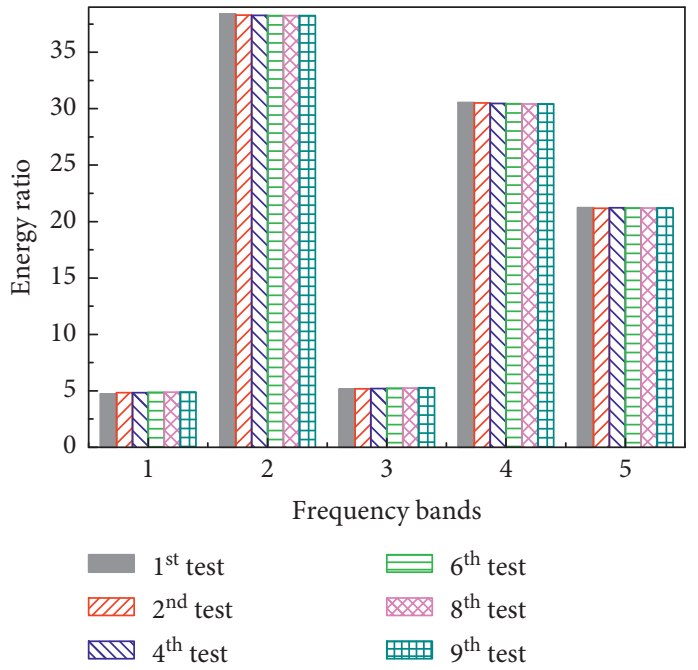

(a)

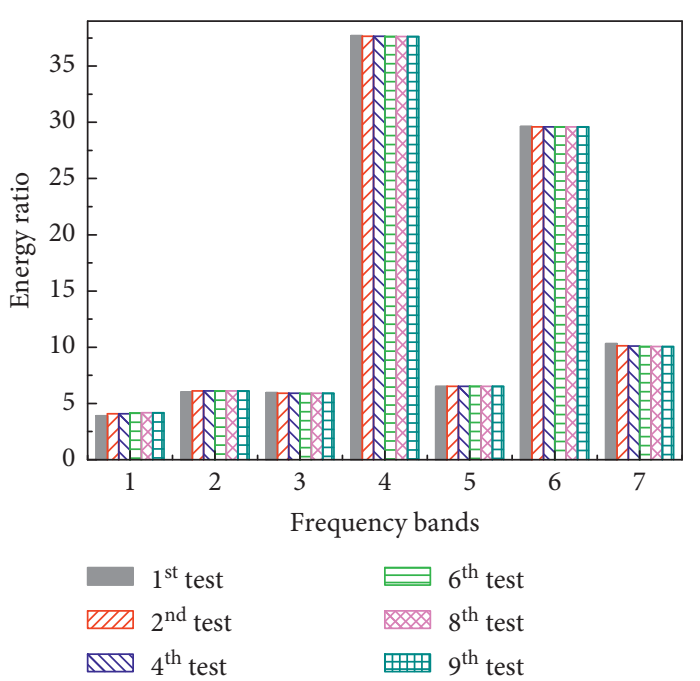

(c)

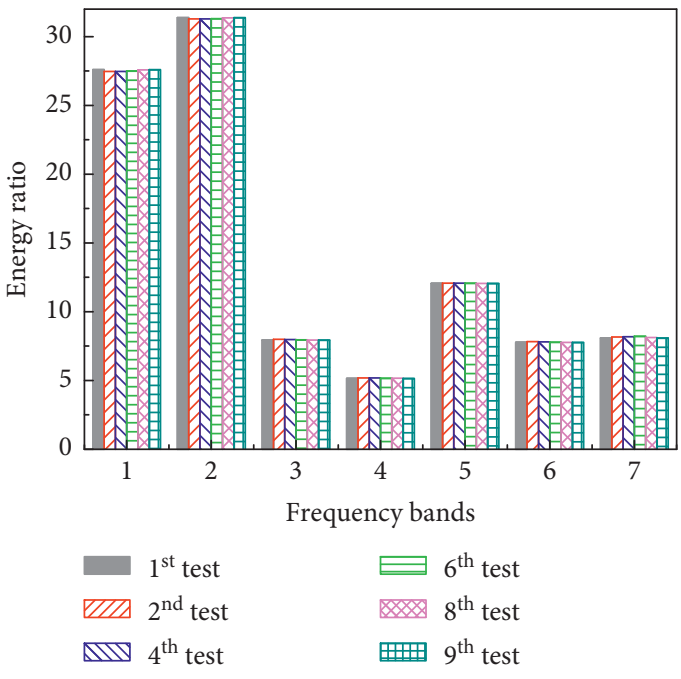

(b)

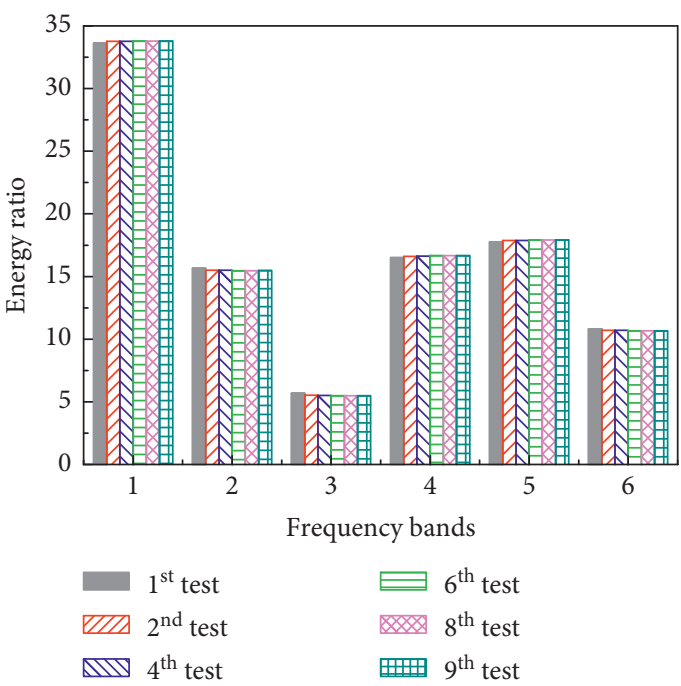

(d)

Figure 22: Hilbert feature vector spectrum in field tests. (a) Point 1. (b) Point 2. (c) Point 5. (d) Point 7. 


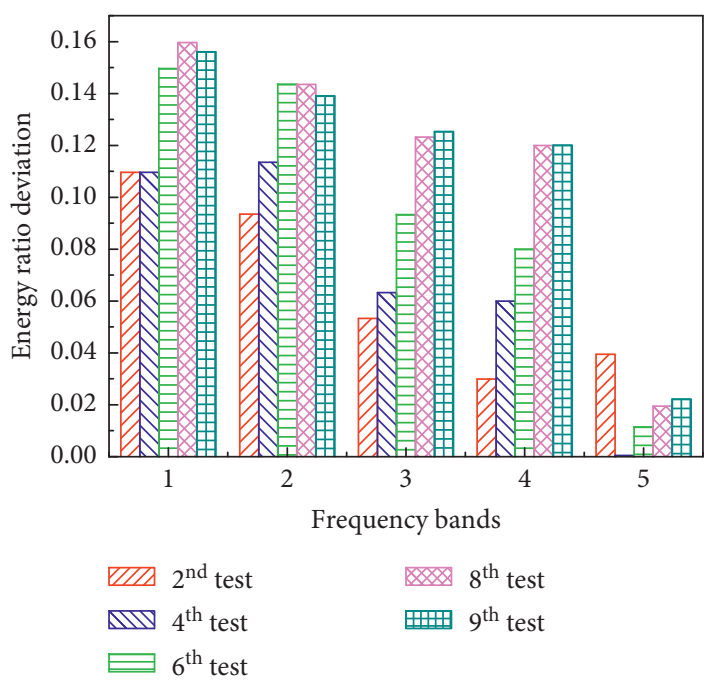

(a)

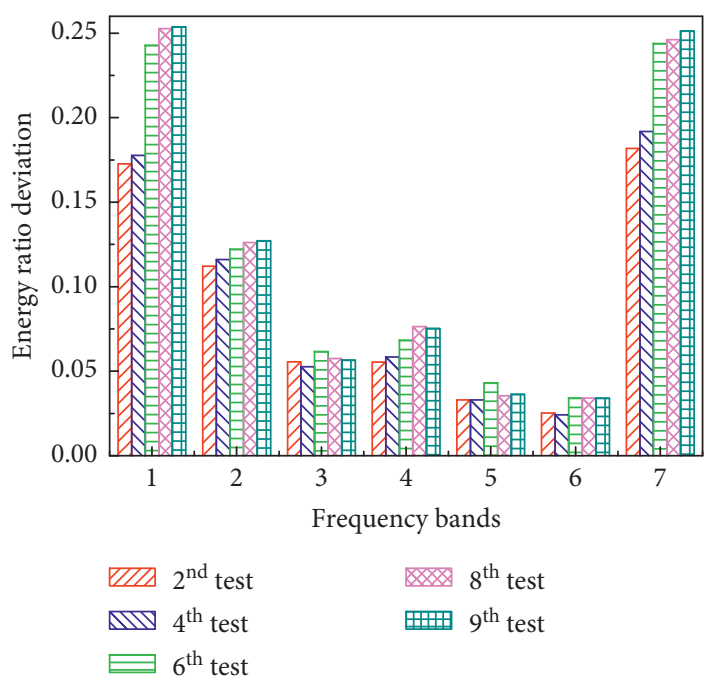

(c)

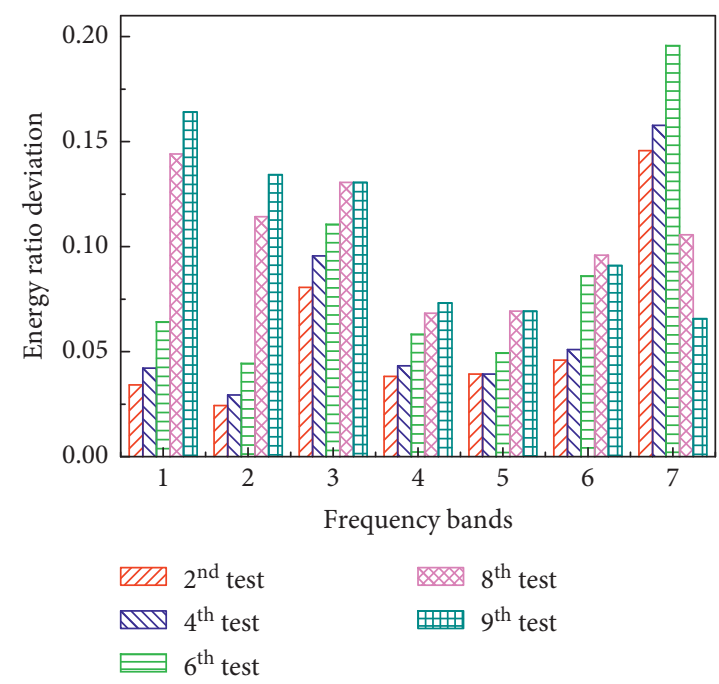

(b)

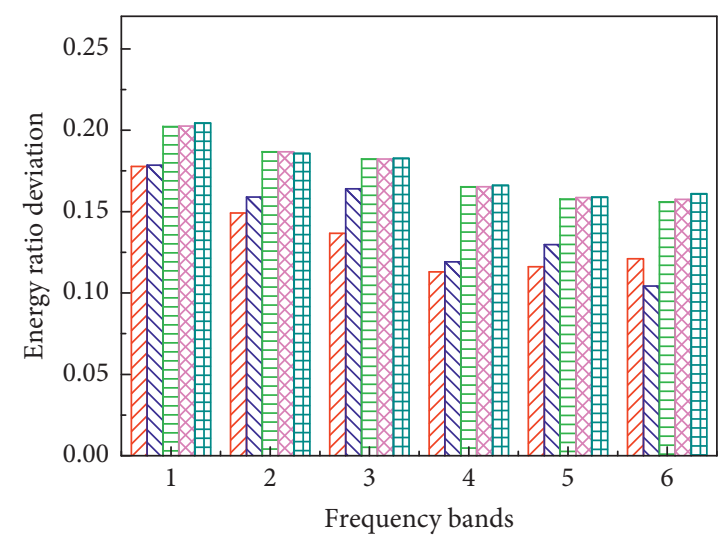

एD $2^{\text {nd }}$ test
$\square=4^{\text {th }}$ test
$\square 6^{\text {th }}$ test

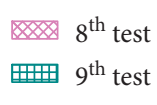

(d)

Figure 23: Hilbert damage feature vector spectrum in field tests. (a) Point 1. (b) Point 2. (c) Point 5. (d) Point 7.

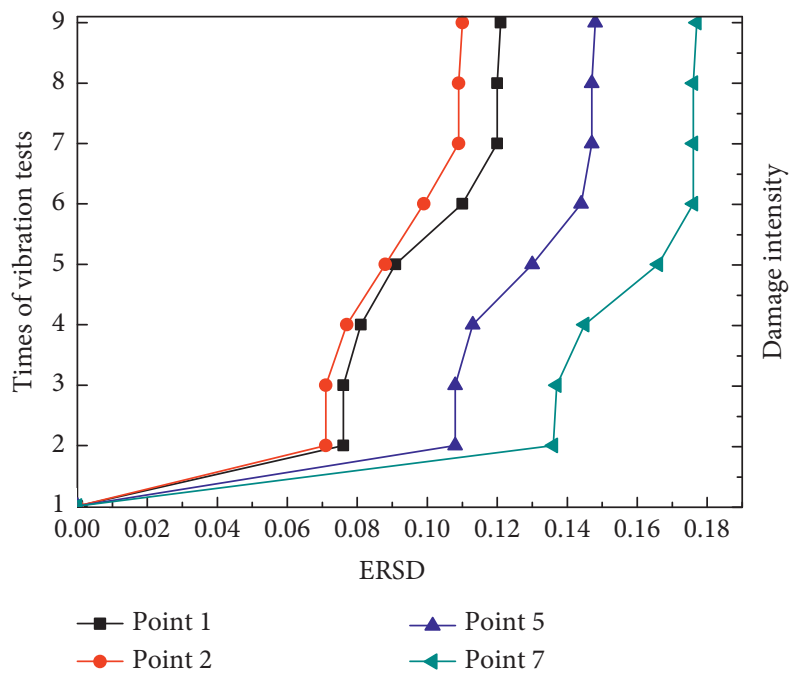

Figure 24: Trend chart of damage alarming indexes in field tests. damage diagnosis method. Whether this method is suitable for diagnosing damages in backfill is needed to be verified in the future.

(2) The damage sensitivity of measuring points is much poorer when the distance between points and partial damages is much larger. Only the points which are very close to partial damages have the best sensitivity to damage. As mentioned above, the measuring points, which are most sensitive to damages, can be used to identify the locations of partial damages within the wall. The damage locations can be easily diagnosed in model tests because the actual damages are known. However, it is difficult to detect the damage location in practical engineering because the simulated damages are unknown. Thus, the precise identification of partial damages requires that sensor locations be adjusted repeatedly, which may be time-consuming. In addition, because the damage intensity can be defined easily in model tests, the quantitative relationship between the 
damage index and damage intensity can be acquired. Thus, the damage intensity of the wall can be identified. Nevertheless, it is difficult to define the form of damage intensity in practical engineering, so the quantitative relationship between the damage index and damage intensity cannot be established easily. Thus, the damage intensity cannot be identified quantitatively.

(3) In comparison with the results in model tests, the distribution characteristics of signal energy in field tests are much better. This may be caused by ambient excitations simulated by hammering in multi-points in model tests. Thus, the way of applying ambient excitations may be updated in model tests. Above all, to identify the damages within practical retaining walls validly, the proposed method is still need to be improved in the future.

\section{Data Availability}

The data used in this paper are available within this article. Based on the tables and figures in this paper, the readers can verify the results of this paper, replicate the analysis, and conduct secondary analyses.

\section{Conflicts of Interest}

The author does not have any conflicts of interest regarding the publication of this paper.

\section{Acknowledgments}

This study was sponsored by the Scientific Research Program funded by General Program (Youth Program) by Shaanxi Provincial Science and Technology Department (no. 2019JQ-883), Science Research Program by Shaanxi Provincial Education Department (no. 17JK0157), and the Talent Start-Up Program founded by Shaanxi University of Technology (no. SLGQD2017-4).

\section{References}

[1] Q. Xu, "Damage identification investigation of retaining wall structures based on a virtual impulse response function," Shock and Vibration, vol. 12, pp. 1-13, 2016.

[2] U. Lee and J. Shin, "A structural damage identification method for plate structures," Engineering Structures, vol. 24, no. 9, pp. 1177-1188, 2002.

[3] D.-G. Kim and S.-B. Lee, "Structural damage identification of a cantilever beam using excitation force level control," $M e$ chanical Systems and Signal Processing, vol. 24, no. 6, pp. 1814-1830, 2010.

[4] X. Zhang, W. Yao, B. Chen, and D. Liu, "Damage identification of a pile based on vibration characteristics," The Scientific World Journal, vol. 20148 pages, 2014.

[5] J.-C. Chen and J. A. Garba, "On-orbit damage assessment for large space structures," AIAA Journal, vol. 26, no. 9, pp. 1119-1126, 1988.

[6] H. Hu, J. Z. Hong, and Z. Y. Liu, "Damage identification for benchmark structure with model updating method based on RFR expansion," Journal of Dynamics and Control, vol. 3, no. 3, pp. 214-218, 2010.
[7] M. Reghavendrachar and A. E. Aktan, "Flexibility by multireference impact testing for bridge," Journal of Structural Engineering, vol. 118, no. 8, pp. 2186-2203, 1992.

[8] Y. L. Ding, A. Q. Li, and C. Q. Miu, "Theoretical research on structural damage alarming of long-span bridges using wavelet packet analysis," Journal of Southeast University (English Edition), vol. 21, no. 4, pp. 459-462, 2005.

[9] W. Qu, W. Song, Y. Xia, Y. Xu, W. Qin, and Z. Jiang, "Twostep method for instability damage detection in tower body of transmission structures," Advances in Structural Engineering, vol. 16, no. 1, pp. 219-232, 2013.

[10] F. Yu, Y. S. Xi, X. N. Tong et al., "Damage identification of an offshore platform based on curvature of modal shape difference and BP neural network," Journal of Vibration and Shock, vol. 30, no. 10, pp. 183-187, 2011.

[11] S. W. Doebling, C. R. Farrar, M. B. Prime, and D. W. Shevitz, "A review of damage identification methods that examine changes in dynamic properties," The Shock and Vibration Digest, vol. 30, no. 2, pp. 91-105, 1998.

[12] P. Cawley and R. D. Adams, "The location of defects in structures from measurement of natural frequencies," The Journal of Strain Analysis for Engineering Design, vol. 14, no. 2, pp. 49-57, 1979.

[13] M. Biswas, A. K. Pandey, and M. M. Samman, "Diagnostic experimental spectral/modal analysis of highway bridge," The International Journal for Analytical and Experimental Modal Analysis, vol. 5, no. 1, pp. 33-42, 1990.

[14] G. Hearn and R. B. Testa, "Modal analysis for damage detection in structures," Journal Structural Engineering, vol. 117, no. 10, pp. 3032-3063, 1991.

[15] C. Zhang, G. Q. Song, and G. Y. Wu, "Structural damage identification by synchronal updating measured modes and finite element model," Journal of Vibration and Shock, vol. 29, no. 9, pp. 1-4, 2010.

[16] Z. H. Zong, F. P. Zhu, and J. Niu, "Damage identification method of bridge structures using response surface based on finite element model updating," China Civil Engineering Journal, vol. 46, no. 2, pp. 115-122, 2013.

[17] J.-H. Chou and J. Ghaboussi, "Genetic algorithm in structural damage detection," Computers \& Structures, vol. 79, no. 14, pp. 1335-1353, 2001.

[18] T. L. Huang and W. X. Ren, "Damage identification of beam structures based on genetic algorithm and sensitivity analysis," Advanced Materials Research, vol. 455-456, pp. 14741479, 2012.

[19] W. L. Qu and W. Chen, "Seismic damage diagnosis of frame structure using artificial neural network," Earthquake Engineering and Engineering Vibration, vol. 22, no. 1, pp. 43-48, 2002.

[20] A. S. Wang, C. B. Liu, and G. B. He, "Detection for existence of structure damage using statistical neural network," China Civil Engineering Journal, vol. 37, no. 8, pp. 24-27, 2004.

[21] Z. Hou, M. Noori, and R. S. Amand, "Wavelet-based approach for structural damage detection," Journal of Engineering Mechanics, vol. 126, no. 7, pp. 677-683, 2000.

[22] Y. Ding, A. Li, and T. Liu, "A study on the WPT-based structural damage alarming of the ASCE benchmark experiments," Advances in Structural Engineering, vol. 11, no. 1, pp. 121-127, 2008.

[23] Y. L. Ding and A. Q. Li, "Experimental research on structure damage alarming of Benchmark structure using wavelet packet analysis," Engineering Mechanics, vol. 25, no. 11, pp. 128-134, 2008. 
[24] J. Zheng and J. Cheng, "Improved Hilbert-Huang transform and its applications to rolling bearing fault diagnosis," Journal of Mechanical Engineering, vol. 51, no. 1, pp. 138-145, 2015.

[25] Q. Ding, G. Meng, and H. G. Li, "Beam damage identification method based on Hilbert-Huang transformation," Journal of Vibration and Shock, vol. 28, no. 9, pp. 108-183, 2009.

[26] N. E. Huang, Z. Shen, S. R. Long et al., "The empirical mode decomposition and the Hilbert spectrum for nonlinear and non-stationary time series analysis," Proceedings of the Royal Society of London. Series A: Mathematical, Physical and Engineering Sciences, vol. 454, no. 1971, pp. 903-995, 1998.

[27] Y. L. Ding and A. Q. Li, "Parameters for identification of wavelet packet energy spectrum for structural damage alarming," Journal of Southeast University (Natural Science Edition), vol. 41, no. 4, pp. 824-828, 2011.

[28] N. E. Huang, M.-L. C. Wu, S. R. Long et al., "A confidence limit for the empirical mode decomposition and Hilbert spectral analysis," Proceedings of the Royal Society of London. Series A: Mathematical, Physical and Engineering Sciences, vol. 459, no. 2037, pp. 2317-2345, 2003.

[29] C. X. Shi and H. S. Li, "Experimental study on damage detection of a girder bridge based on Hilbert marginal spectrum and random-fuzzy statistics principle," Journal of Vibration and Shock, vol. 30, no. 8, pp. 123-127, 2011.

[30] C. X. Shi, Hilbert-Huang Transform and its Application in Structural Analysis, Tongji University, Shanghai, China, 2004.

[31] Y. H. An, Several New Methods for Vibration-Based Damage Identification of Structures, Dalian University of Technology, Dalian, China, 2013.

[32] H. D. Xu, L. H. Wang, and Z. D. Hu, "Quantitative identification of wood beam damage using modal curvature theory," Journal of Vibration, Measurement, \& Diagnosis, vol. 31, no. 1, pp. 110-114, 2011.

[33] H. Y. Zhang, D. Han, F. Wang et al., Hilbert-Huang Transform and its Application, National Defense Industry Press, Beijing, China, 2017. 


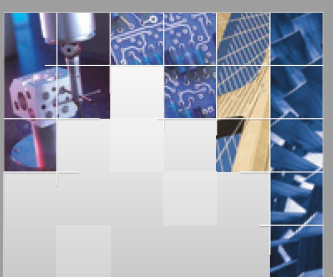

\section{Enfincering}
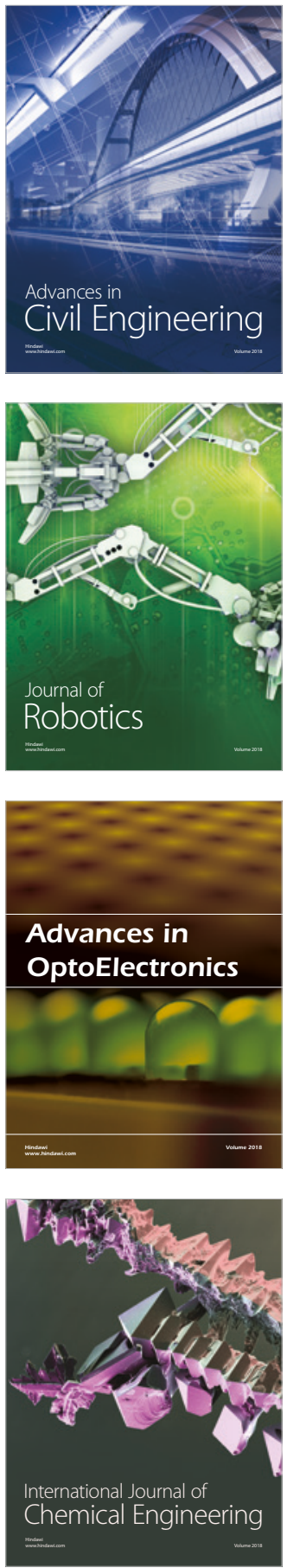

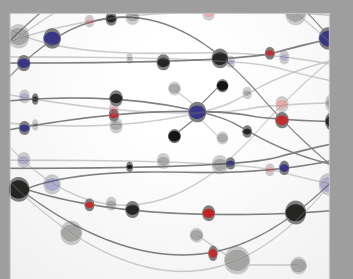

\section{Rotating \\ Machinery}

The Scientific World Journal

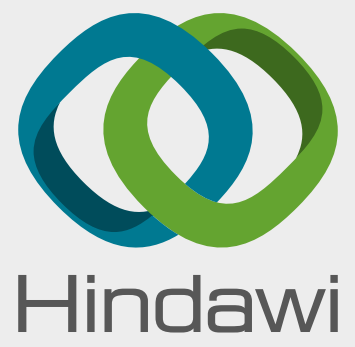

Submit your manuscripts at

www.hindawi.com
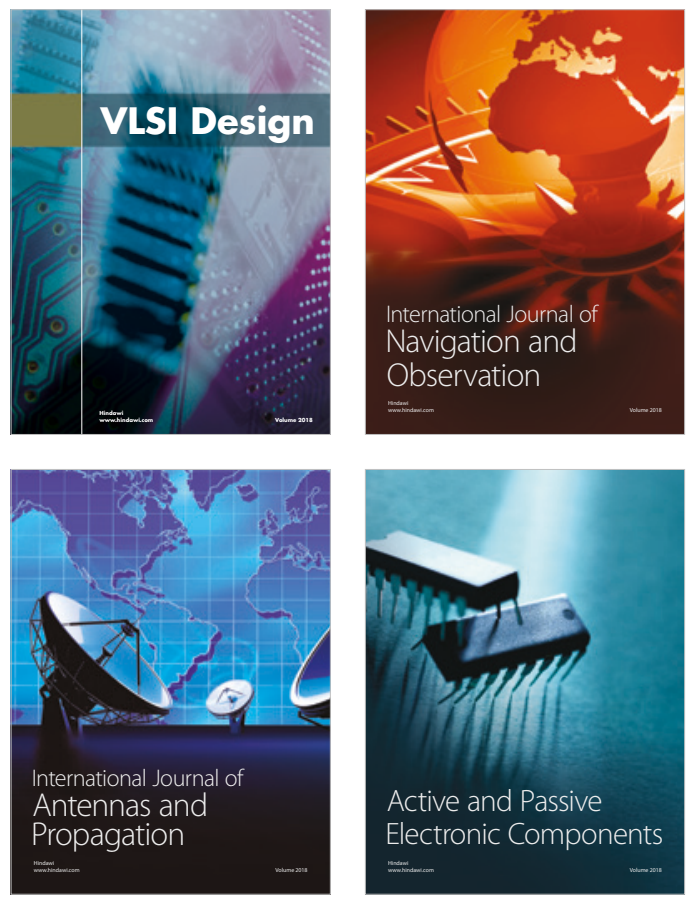
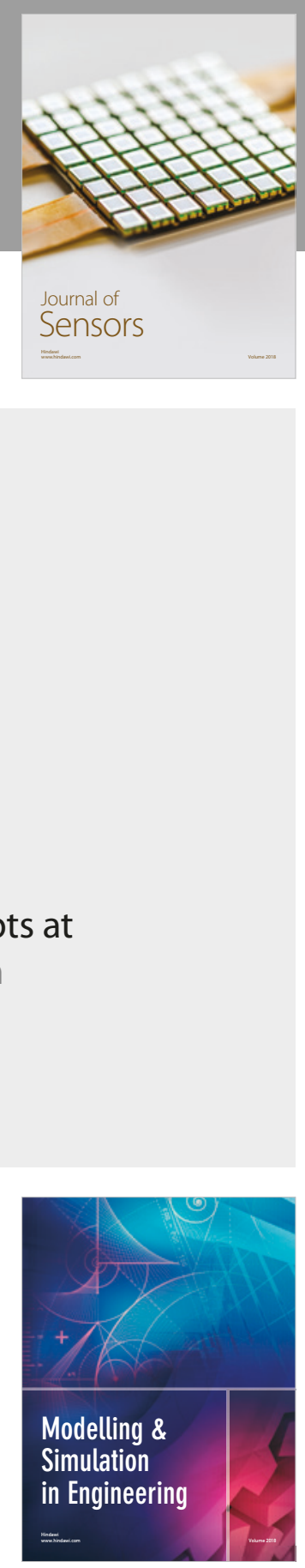

\section{Advances \\ Multimedia}
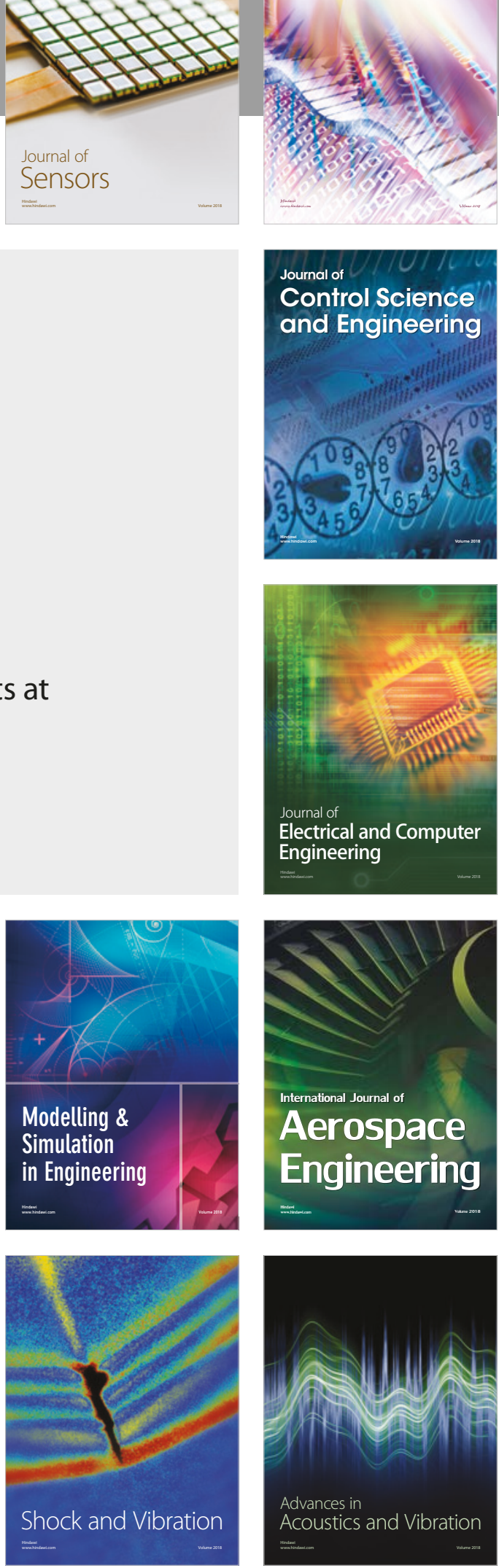